\title{
Development and characterization of stable anaerobic thermophilic methanogenic microbiomes fermenting switchgrass at decreasing residence times
}

\author{
Xiaoyu Liang ${ }^{1,2+} \mathbb{D}^{0}$, Jason M. Whitham ${ }^{2,3+}$, Evert K. Holwerda ${ }^{1,2}$, Xiongjun Shao ${ }^{1,2}$, Liang Tian ${ }^{1,2}$, Yu-Wei Wu ${ }^{4}$, \\ Vincent Lombard ${ }^{5,6}$, Bernard Henrissat ${ }^{5,6,7}$, Dawn M. Klingemann 2,3, Zamin K. Yang ${ }^{3}$, Mircea Podar ${ }^{3}$, \\ Tom L. Richard ${ }^{8}$, James G. Elkins ${ }^{2,3}$, Steven D. Brown ${ }^{2,3,9}$ and Lee R. Lynd ${ }^{1,2^{*}}$
}

\begin{abstract}
Background: Anaerobic fermentation of lignocellulose occurs in both natural and managed environments, and is an essential part of the carbon cycle as well as a promising route to sustainable production of fuels and chemicals. Lignocellulose solubilization by mixed microbiomes is important in these contexts.

Results: Here, we report the development of stable switchgrass-fermenting enrichment cultures maintained at various residence times and moderately high $\left(55^{\circ} \mathrm{C}\right)$ temperatures. Anaerobic microbiomes derived from a digester inoculum were incubated at $55^{\circ} \mathrm{C}$ and fed semi-continuously with medium containing $30 \mathrm{~g} / \mathrm{L}$ mid-season harvested switchgrass to achieve residence times (RT) of 20, 10, 5, and 3.3 days. Stable, time-invariant cellulolytic methanogenic cultures with minimal accumulation of organic acids were achieved for all RTs. Fractional carbohydrate solubilization was $0.711,0.654,0.581$ and 0.538 at $R T=20,10,5$ and 3.3 days, respectively, and glucan solubilization was proportional to xylan solubilization at all RTs. The rate of solubilization was described well by the equation $r=k\left(C-C_{0} f_{r}\right)$, where $C$ represents the concentration of unutilized carbohydrate, $C_{0}$ is the concentration of carbohydrate (cellulose and hemicellulose) entering the bioreactor and $f_{r}$ is the extrapolated fraction of entering carbohydrate that is recalcitrant at infinite residence time. The 3.3 day RT is among the shortest RT reported for stable thermophilic, methanogenic digestion of a lignocellulosic feedstock. $16 \mathrm{~S}$ rDNA phylotyping and metagenomic analyses were conducted to characterize the effect of RT on community dynamics and to infer functional roles in the switchgrass to biogas conversion to the various microbial taxa. Firmicutes were the dominant phylum, increasing in relative abundance from 54 to $96 \%$ as RT decreased. A Clostridium clariflavum strain with genetic markers for xylose metabolism was the most abundant lignocellulose-solubilizing bacterium. A Thermotogae (Defluviitoga tunisiensis) was the most abundant bacterium in switchgrass digesters at RT $=20$ days but decreased in abundance at lower RTs as did multiple Chloroflexi. Synergistetes and Euryarchaeota were present at roughly constant levels over the range of RTs examined.
\end{abstract}

Conclusions: A system was developed in which stable methanogenic steady-states were readily obtained with a particulate biomass feedstock, mid-season switchgrass, at laboratory $(1 \mathrm{~L})$ scale. Characterization of the extent and rate of carbohydrate solubilization in combination with $16 \mathrm{~S}$ rDNA and metagenomic sequencing provides a multidimensional view of performance, species composition, glycoside hydrolases, and metabolic function with varying

\footnotetext{
*Correspondence: lee.r.lynd@dartmouth.edu

${ }^{+}$Xiaoyu Liang and Jason M. Whitham contributed equally to this work

${ }^{1}$ Thayer School of Engineering, Dartmouth College, Hanover, NH 03755,

USA

Full list of author information is available at the end of the article
}

(c) The Author(s) 2018. This article is distributed under the terms of the Creative Commons Attribution 4.0 International License (http://creativecommons.org/licenses/by/4.0/), which permits unrestricted use, distribution, and reproduction in any medium, provided you give appropriate credit to the original author(s) and the source, provide a link to the Creative Commons license, and indicate if changes were made. The Creative Commons Public Domain Dedication waiver (http://creativecommons.org/ publicdomain/zero/1.0/) applies to the data made available in this article, unless otherwise stated. 
residence time. These results provide a point of reference and guidance for future studies and organism development efforts involving defined cultures.

Keywords: Lignocellulose, Anaerobic, Methanogenic, Thermophilic, Solubilization, Microbial communities, Metagenomics, Clostridium clariflavum

\section{Background}

Anaerobic fermentation of lignocellulose is a fundamental microbial process with central importance to the global carbon cycle, digestion of anthropogenic wastes, ruminants and wood-eating insects; it is also of interest in the context of sustainable production of heat, electricity, fuels and chemicals $[1,2]$. In all these systems, solubilizing solid plant fiber is a prerequisite first step in order for components thereof to be biologically transformed, and is generally rate-limiting to performance and function $[1,3]$.

Rates of lignocellulose solubilization vary widely depending on the feedstock, bioreactor configuration, and operating conditions, but generally increase with increasing temperature for both pure cultures $[3,4]$ and consortia [5-7]. The rate of cellulose (Avicel) solubilization by pure cultures of Ruminiclostridium thermocellum (formerly Clostridium thermocellum) is proportional to cell concentration at the start of a batch culture and the remaining substrate concentration during the later stages, with specific growth rate exhibiting a maximum and variable throughout digestion [8]. Lignocellulose digestion is commonly modeled as first-order kinetics in substrate, expressed in terms of either remaining carbohydrate or biogas production $[9,10]$. A transition from methanogenic to acidogenic digestion has often been observed to accompany operation at low residence times (RT) $[11,12]$, with previous studies generally reporting volatile fatty acids (VFAs) as the dominant products for RTs less than 5 days [13-16].

Lignocellulose-degrading microbiomes are typically dominated by Firmicutes, Bacteroidetes, and Proteobacteria [17-19]. Community analyses indicate lower diversity and higher relative abundance of cellulolytic and xylanolytic species at thermophilic temperatures [13, $20,21]$. The presence and role of members in lignocellulosic communities has often been inferred from genomic potential [17, 22-25], based upon gene expression, biochemical and activity studies of analogous enzyme systems [26-29]. Isolation and thorough characterization of microbes and enzymes are slower approaches than system-based techniques, which generate large amounts of data on many uncultured microbes and potentially novel carbohydrate-active enzymes (CAZymes) [30-33]. Enzymes containing multiple CAZyme modules with related substrate specificities have been shown to act synergistically and are more effective at degrading substrates than non-modular enzymes [3, 34, 35]. Enzyme synergy is further improved when multiple modular enzymes are docked onto a protein scaffold to form a cellulosome or are otherwise collocated [36, 37]. As more CAZymes are characterized, a greater breadth of substrate specificities are being found within enzyme families, impeding direct functional annotation [29]. Several studies have concluded that microbes with a greater diversity and number of CAZymes have higher lignocellulosic deconstruction activities than ones with less extensive inventories [38-42].

In the context of liquid biofuel production, lignocellulose solubilization by mixed microbiomes provides guidance for the development of industrial processes using defined cultures; in particular by providing a standard of comparison for pure culture studies, insights into the mechanisms operative in microbiomes, and a potential source of new biocatalysts with desirable properties [43, 44]. Motivated by these factors, we undertook to develop stable, thermophilic, lignocellulose-fermenting, methanogenic microbiomes fed at regular intervals. We report here carbohydrate solubilization, methane production, production of organic acids, and community characterization over a range of RTs. Solubilization kinetics and the relationship between cellulose and xylan solubilization were also examined.

\section{Methods}

Switchgrass feedstock characterization and preparation Mid-season switchgrass (Panicum virgatum L., Cave in Rock) harvested in June, 2012 at Rock Springs Research Farm (Spring Mills, PA) and obtained via the Richard lab at Pennsylvania State University was used as the substrate in this study. Upon harvesting, the switchgrass was airdried indoors for 2 weeks and subsequently stored under dry and dark conditions in mesh bags. Above-ground plants including stalks were milled to $2 \mathrm{~mm}$ in a ED-5 Wiley Mill (Thomas Scientific, Swedesboro, NJ), which was used for initial enrichment and inoculum preparation (described below). The $2 \mathrm{~mm}$ switchgrass was milled in a ZM200 centrifugal milling machine (Retsch, Haan, Germany) to a cut-off size of $0.5 \mathrm{~mm}$ and used for this study. All milled switchgrass passed through a $0.5 \mathrm{~mm}$ screen. The moisture level, chemical oxygen demand (COD), ash and carbohydrate content of the milled 
switchgrass $(0.5 \mathrm{~mm})$ is summarized in Table 1 . Moisture level was analyzed by A\&D MX-50 Moisture Analyzer (A\&D Company, San Jose, CA). Ash content was determined by Vulcan 3-550 Muffle Furnace (DENTSPLY Ceramco, York, PA) according to the method described in [45]. COD was measured with the method described below. The total carbohydrate content of switchgrass was measured by quantitative saccharification, which is described below, and reported as glucose, xylose and arabinose.

\section{Initial enrichment and inoculum preparation}

For the initial enrichment inoculum, a digestate sample was obtained from a two-stage (aerobic then anaerobic) digester located at Vermont Technical College (http:// digester.vtc.edu/, Randolph, Vermont), which was fed a mixture of farm manure and clean food waste residuals and running at mesophilic temperature. To prepare the inoculum, digestate $(450 \mathrm{~mL})$ was suspended in $550 \mathrm{~mL}$ of water with $30 \mathrm{~g}$ of switchgrass in a $1.5 \mathrm{~L}$ of bioreactor (described below in "Fermentation system" section). Effluent removal and feeding were performed daily over a period of 4 months. The inoculum reactor was fed $30 \mathrm{~g} / \mathrm{L}$ of mid-season harvested switchgrass milled to $2 \mathrm{~mm}$ and water, with no other medium components. The residence time (RT) was 20 days for the first 112 days, and 14 days for the last 14 days. This enrichment period at $55{ }^{\circ} \mathrm{C}$ allowed a thermophilic switchgrass-fermenting community to develop and also ensured that the concentration of solids present in the original inoculum was vanishingly small by the time bioreactor studies were initiated. From this initial enrichment, three $200 \mathrm{~mL}$ broth liquid samples were obtained for subsequent bioreactor studies described below.

\section{Fermentation medium components}

The following stock solutions were used: Wolfe's modified elixir stock solution $(50 \times)$ [46] contains the following chemicals in water at the indicated

Table 1 Moisture level, COD, carbohydrate and ash content of the milled switchgrass (Results are expressed as mean \pm SD)

\begin{tabular}{lc}
\hline Parameters & Switchgrass value \\
\hline Moisture & $6.05 \% \pm 0.3 \%$ \\
Total COD (g/g switchgrass) & $1.22 \pm 0.01$ \\
Glucose & $30.6 \% \pm 1.4 \%$ \\
Xylose & $22.9 \% \pm 1.0 \%$ \\
Arabinose & $4.07 \% \pm 0.2 \%$ \\
Ash & $5.92 \% \pm 0.05 \%$ \\
\hline
\end{tabular}

The COD, carbohydrate and ash content values are for switchgrass inclusive of $6.05 \%$ moisture concentrations in gram per liter: nitrilotriacetic acid (NTA), $1.5 ; \quad \mathrm{MgSO}_{4} \cdot 7 \mathrm{H}_{2} \mathrm{O}, \quad 3.0 ; \quad \mathrm{MnSO}_{4} \cdot \mathrm{H}_{2} \mathrm{O}, \quad 0.5$; $\mathrm{NaCl}, \quad 1.0 ; \quad \mathrm{FeSO}_{4} \cdot 7 \mathrm{H}_{2} \mathrm{O}, \quad 0.1 ; \mathrm{Co}\left(\mathrm{NO}_{3}\right)_{2} \cdot 6 \mathrm{H}_{2} \mathrm{O}, \quad 0.1$; $\mathrm{CaCl}_{2} \cdot 2 \mathrm{H}_{2} \mathrm{O}, 0.1 ; \mathrm{ZnSO}_{4} \cdot 7 \mathrm{H}_{2} \mathrm{O}, 0.1 ; \mathrm{NiCl}_{2} \cdot 6 \mathrm{H}_{2} \mathrm{O}, 0.05$; $\mathrm{CuSO}_{4} \cdot 5 \mathrm{H}_{2} \mathrm{O}, 0.01 ; \mathrm{AlK}\left(\mathrm{SO}_{4}\right)_{2} \cdot 12 \mathrm{H}_{2} \mathrm{O}, 0.01 ; \mathrm{H}_{3} \mathrm{BO}_{3}, 0.01$; $\mathrm{Na}_{2} \mathrm{MoO}_{4} \cdot 2 \mathrm{H}_{2} \mathrm{O}, 0.01 ; \mathrm{Na}_{2} \mathrm{WO}_{4} \cdot 2 \mathrm{H}_{2} \mathrm{O}, 0.01 ; \mathrm{Na}_{2} \mathrm{SeO}_{4}$, 0.001 ; complete volume with Milli-Q water. Wolfe's vitamin solution $(50 \times)$ [46] contains the following chemicals in water at the indicated concentrations in milligram per liter: biotin, 2.0; folic acid, 2.0; pyridoxine hydrochloride, 10.0; thiamine $\mathrm{HCl}, 5.0$; riboflavin, 5.0 ; nicotinic acid, 5.0; calcium $\mathrm{D}-(+)$-pantothenate, 5.0; vitamin $\mathrm{B}_{12}, 0.1$; $p$-aminobenzoic acid, 5.0; thioctic acid, 5.0; complete volume with Milli-Q water. Ammonium and phosphate stock solution $(50 \times)$ contains $50 \mathrm{~g} / \mathrm{L} \mathrm{NH}_{4} \mathrm{Cl}$ and $25 \mathrm{~g} / \mathrm{L}$ $\mathrm{KH}_{2} \mathrm{PO}_{4}$. Iron stock solution $(1000 \times)$ contains $37 \mathrm{~g} / \mathrm{L}$ $\mathrm{FeCl}_{2} \cdot 4 \mathrm{H}_{2} \mathrm{O}$ in acidified water $(500 \mu \mathrm{L}$ of $12.1 \mathrm{~N} \mathrm{HCl}$ was added to per $50 \mathrm{~mL}$ of water) to avoid oxidation. The solutions were either autoclaved (iron stock solution) or filter-sterilized (all other stock solutions). Switchgrass was added (without sterilization) to a concentration of $30 \mathrm{~g} / \mathrm{L}$ (as-is basis with 6.05\% moisture), and the $\mathrm{pH}$ of the medium was adjusted to $\mathrm{pH} 7.5$ during each feeding event with $1 \mathrm{~N}$ sodium hydroxide solution.

\section{Fermentation system}

Both the initial enrichment and subsequent bioreactor studies (R1, R2 and R3) were carried out in $1.5 \mathrm{~L}$ bioreactors (without sterilization) with a working volume of $1 \mathrm{~L}$ and operated by a Qplus multi-bioreactor system (Sartorius Stedim, Bohemia NY). The bioreactors were stirred at $280 \mathrm{rpm}$. The temperature was controlled at $55{ }^{\circ} \mathrm{C}$ by a circulating Polystat water bath system (ColeParmer, Vernon Hills, IL). Software accompanying the Qplus bioreactor system was used to record data for $\mathrm{pH}$, base addition, temperature and stirrer speed. The $\mathrm{pH}$ was monitored using an InPro3253/225/Pt100 pH probe (Mettler-Toledo, $\mathrm{OH}$ ). The $\mathrm{pH}$ of the growth medium fed to the reactors R1, R2 and R3 was adjusted to 7.5 at room temperature, which was sufficient to keep the reactor $\mathrm{pH}$ above 6.0 for all residence times. After manual adjustment of medium $\mathrm{pH}$, automatic base addition in general did not occur during reported steady states. Occasional base addition took place in transients following changes in the RT.

\section{Fermentation start up and operation}

Bioreactor studies of switchgrass-fermenting microbiomes were initiated by manually adding pre-sterilized $20 \mathrm{~mL}$ Wolfe's modified elixir stock solution, $20 \mathrm{~mL}$ Wolfe's vitamin solution, $20 \mathrm{~mL}$ ammonium and phosphate stock solution, and $1 \mathrm{~mL}$ iron stock solution to $30 \mathrm{~g}$ mid-season switchgrass prepared as above in sterile 
milliQ water. Effort was made to minimize contamination but the medium addition procedure was not aseptic. As an inoculum, $200 \mathrm{~mL}$ of broth liquid obtained from the enrichment reactor (described above) was added to a total volume of $1 \mathrm{~L}$. Reactors were purged with $\mathrm{N}_{2}$ before and $30 \mathrm{~min}$ after inoculation. Reactors were operated semi-continuously by removing $100 \mathrm{~mL}$ of slurry (sample used for analysis) first and immediately after that adding $100 \mathrm{~mL}$ of medium at a frequency of 10 times per RT at equal time intervals.

Bioreactors R1, R2, and R3 were operated for 214 days following inoculation. R1 was maintained at RT 20 days. Reactors $\mathrm{R} 2$ and $\mathrm{R} 3$ were run at $\mathrm{RT}=20$ days for 110 days, $\mathrm{RT}=10$ days for 50 days, $\mathrm{RT}=5$ days for 40 days and $\mathrm{RT}=3.3$ days for 14 days. Reactors were considered to have reached steady state after 3 RTs. From data presented in Fig. 1, stable biogas production occurred much sooner at 2 RTs (see also Additional file 1: Figure S1). For R1 and R3, slurry was withdrawn via a $50 \mathrm{~mL}$ pipette by removing a plug from the head plate. For R2, slurry was withdrawn by means of a $4 \mathrm{~mm}$ internal diameter stainless steel tube extending into the broth. Although the sampling procedure used for R2 was accompanied by less exposure of the culture to oxygen than the procedure used for R3, results were very similar for all variables monitored. In support of this statement, the maximum difference over the range of 4 residence times was tested with respect to mean fractional solubilization (0.026) and gas composition $\left(1.6 \% \mathrm{CH}_{4}\right.$ and $2.4 \%$ $\mathrm{CO}_{2}$ ) (see data in Additional file 2: Table S1, Additional file 3: Table S2 and Additional file 4: Table S3). Separate control experiments for testing sampling uniformity indicated that the concentration of solids removed by both methods was equal.

\section{Biogas measurement}

The biogas production rate was measured using a wet tip gas meter (http://wettipgasmeter.com/meters.php) filled with water acidified using either $\mathrm{H}_{2} \mathrm{SO}_{4}$ or $\mathrm{HCl}$ until $\mathrm{pH}<2$. Data were manually recorded or recorded by a data logger (HOBO Pendant Event, $64 \mathrm{~K}$, Onset Computer Corporation, Pocasset, MA) at each reactor feeding. To measure the concentration of $\mathrm{CH}_{4}, \mathrm{CO}_{2}, \mathrm{H}_{2}$ and $\mathrm{N}_{2}$ gas a $0.1-0.5 \mathrm{~mL}$ gas sample was taken from a gas-sampling port in the gas-out line between the reactor and the gas tip meter and analyzed with a model 310 Educational Gas Chromatograph (SRI Instruments, Torrance, $\mathrm{CA}$ ) with a thermal conductivity detector using a $1.8 \mathrm{~m} \times 3 \mathrm{~mm}\left(6^{\prime} \times 1 / 8^{\prime \prime}\right)$ S.S. HayeSep D packed column (SRI Instruments, Torrance, CA). Helium $(20 \mathrm{~mL} /$ min) was used as carrier gas for $\mathrm{CH}_{4}, \mathrm{CO}_{2}$ and $\mathrm{N}_{2}$ with the column at $40{ }^{\circ} \mathrm{C}$. Nitrogen $(13.5 \mathrm{~mL} / \mathrm{min})$ was used as carrier gas for $\mathrm{H}_{2}$ analysis with the column at $50{ }^{\circ} \mathrm{C}$. For all gas analyses the detector was at $150{ }^{\circ} \mathrm{C}$.

\section{Fractional carbohydrate solubilization}

Broth samples were centrifuged $(10 \mathrm{~min}$ at $2800 \times g)$ and the pellets were freeze-dried overnight in a lyophilizer (Labconco, Kansas City, MO). Total carbohydrate content (glucan, xylan and arabinan) of the initial switchgrass material and the harvested residuals was determined by quantitative saccharification as described in [47] and adapted elsewhere [48]. The carbohydrate content of microbes is on the order of $2 \%(w / w)$ of the cell dry weight, and was considered to have a negligible contribution to the total carbohydrate content. The hydrolyzed sugars were analyzed by HPLC (Waters, Milford, MA) with an Aminex HPX-87H column (Bio-Rad, Hercules, CA) at $60{ }^{\circ} \mathrm{C}$ and detected by refractive index. HPLC eluent was $5 \mathrm{mM}$ sulfuric acid with a flow rate of $0.6 \mathrm{~mL} / \mathrm{min}$. Fractional carbohydrate solubilization, FCS, was calculated using the following equation, with carbohydrate on a soluble monomer equivalent basis:

$$
\begin{aligned}
F C S & =\frac{\text { Mass carbohydrate initial }- \text { mass carbohydrate final }}{\text { Mass carbohydrate initial }} \\
& =\frac{R_{\mathrm{o}} \times S_{\mathrm{o}}-C \times V}{R_{\mathrm{o}} \times S_{\mathrm{o}}}
\end{aligned}
$$

where $R_{\mathrm{o}}$ denotes the mass ratio of carbohydrate per dry solids (g monomer equivalent/g dry solids), $S_{\mathrm{o}}$ denotes the solid concentration $(\mathrm{g} / \mathrm{L}), C$ denotes the concentration of carbohydrate in the reactor ( $\mathrm{g}$ monomer equivalent/L), and $V$ denotes the volume of the reactor. $R_{\mathrm{o}}$ and $C$ are calculated for either total carbohydrate, glucan, or xylan as indicated in the text. All measurements were conducted in duplicate. Steady-state solubilization data reported in Fig. 3 are based on averages of two or more samples taken after at least three residence times following a change in residence time as detailed in Additional file 4: Table S3.

\section{Quantification of volatile fatty acids (VFA)}

Liquid samples (filtered) were analyzed by HPLC with an Aminex HPX-87H column at $60{ }^{\circ} \mathrm{C}$ as described above for formic acid, acetic acid, propionic acid, butyric acid, iso-butyric acid and valeric acid. HPLC eluent was $5 \mathrm{mM}$ sulfuric acid with a flow rate of $0.6 \mathrm{~mL} / \mathrm{min}$. All measurements were conducted in duplicate against a known standard (volatile-free acid mix standard, 46975-U SUPELCO, Sigma-Aldrich).

\section{Mass and electron balances}

Bioreactor mass balances were calculated based on the mass flow rate of methane and $\mathrm{CO}_{2}$ and freeze-dried slurry leaving the reactor as a percentage of the dry 
weight of switchgrass added per day. $\mathrm{CO}_{2}$ leaving the reactor included dissolved $\mathrm{CO}_{2}$ calculated as described by Baskaran [49]. Bioreactor electron balances were calculated based on the mass flow rate of COD of methane and slurry leaving the reactor as a percentage of the COD of the switchgrass and liquid medium added per day. The COD of switchgrass and slurry leaving the reactor was measured using Digestion Solution for COD 20-1500 mg/L Range and Digital Reactor Block 200 (Hach Company, CO). The COD of the liquid medium was $<1 \%$ of the COD of switchgrass fed to the reactor. All measurements were conducted in duplicate.

\section{DNA isolation and $16 \mathrm{~S}$ rDNA sequencing}

DNA was isolated from pelleted microbial cells, without separation of residual biomass, using the PowerLyzer Powersoil DNA Isolation kit from MoBio Laboratories Inc. (Carlsbad, CA) following the manufacturer's protocol as has previously been used to investigate methanoarchaea in environmental and anaerobic digester communities [50]. Cells were lysed using a Precellys 24 high-throughput tissue homogenizer (Bertin Technologies, Montigny-le-Bretonneux, France) at $6200 \mathrm{rpm}$ for one 45-s pulse. DNA was eluted in $100 \mu \mathrm{L}$ of water and quality/quantity was assessed by Nanodrop analysis (Thermo Scientific, Wilmington, DE) and on a $1 \%$ agarose gel.

The 16S rDNA amplicon pool was prepared according to the Lundberg et al. [51] method with the following modification [52]. For template tagging, 5 cycles of amplification were performed by denaturing the reaction at $95^{\circ} \mathrm{C}$ for $1 \mathrm{~min}$, annealing at $50^{\circ} \mathrm{C}$ for $2 \mathrm{~min}$, extension at $72{ }^{\circ} \mathrm{C}$ for $2 \mathrm{~min}$ and cooled down to $4{ }^{\circ} \mathrm{C}$. The product was purified with $17 \mu \mathrm{L}$ of Agencourt Ampure XP beads (Beckman Coulter, Brea, CA) and eluted in $21 \mu \mathrm{L}$ of water. The primers for tagging were a mixture of $515 \mathrm{~F}$ (5' GTGCCAGCMGCCGCGGTAA) and 806R (5' GGA CTACHVGGGTWTCTAA) for $16 \mathrm{~S}$ rDNA V4 region. Because the "universal" primer 515F does not effectively amplify several groups of Archaea and Bacteria, we supplemented it with modified versions that included 10\% 515FArch (5' GTGKCAGCMGCCGCGGTAA) and 3\% TM7 (5' GTGCCAGCMGCCGCGGTCA). For the second PCR step, $20 \mu \mathrm{L}$ of purified DNA from the previous step was used in a $50 \mu \mathrm{L}$ reaction. Purified DNA was tagged with barcoded forward and reverse PCR primers. The PCR program was 1 cycle at $95{ }^{\circ} \mathrm{C}$ for $45 \mathrm{~s}$ and 32 cycles at $95{ }^{\circ} \mathrm{C}$ for $15 \mathrm{~s}$, annealing at $60{ }^{\circ} \mathrm{C}$ for $30 \mathrm{~s}$, and $72{ }^{\circ} \mathrm{C}$ for $30 \mathrm{~s}$. For sequencing, the DNA samples were pooled together and purified with Agencourt Ampure $\mathrm{XP}$ beads (beads to DNA, 0.7 to 1 ratio). The concentration of the 16S rDNA amplicon pool was determined by Qubit using the broad range double-stranded DNA assay (Life Technologies, Carlsbad, CA). The amplicon pool and PhiX were diluted and denatured following the manufacturer's protocol (Illumina, San Diego, CA, Part \# 15039740 Rev. D). The final sequencing concentration was 9 pM with $80 \%$ amplicon pool and 20\% PhiX. Paired end sequencing $(2 \times 251 \mathrm{bp})$ was completed on an Illumina MiSeq instrument (San Diego, CA) with a v2 500 cycle kit.

\section{Read processing, OTU assignment and phylogenetic analysis}

Partial 16S rDNA sequencing reads were preprocessed, operational taxonomic units (OTUs) were selected and diversity metrics calculated using the methods and pipelines described in [53]. Briefly, reads were trimmed of primers with Cutadapt (v.1.9.1) [54], and then processed using a combination of UPARSE [55] and QIIME (v.1.9.1) [56]. Quality filtering of OTUs less $0.0001 \%$ was performed in accordance with recommendations from [57], and counts were subsequently rarefied to the lowest sample OTU count, 74597. Diversity metrics were visualized with MacQIIME 1.9.1 [56] and Emperor 0.9.51 plots [58]. Data were deposited into the National Center for Biotechnology Information (NCBI) Sequence Read Archive under Bioproject PRJNA395747.

Partial 16S rDNA sequences of OTUs with greater than $1 \%$ average relative abundance were aligned with the most similar cultured species found in the non-redundant NCBI database (March 1, 2016) using MUSCLE 3.8.425 (10 iterations) [59] in Geneious 8.1.5 [60]. PhyML [61] was used to construct a maximum likelihood tree, with the following parameters: generalized time reversible (GTR) substitution model with four substitution rate categories under gamma distribution, with rates inferred from the data and with no invariable sites. The tree topology was determined using nearest neighbor interchange and optimization for topology/length/rate, the node support values were determined by bootstrapping (100 bootstraps).

\section{Metagenome sequencing}

DNA isolated from 15 samples was sent to US Department of Energy's Joint Genome Institute for metagenome sequencing under proposal ID 502908. DNA (100 ng) was sheared to 300 bp using the Covaris LE220 and size selected using SPRI beads (Beckman Coulter). The fragments were treated with end-repair, A-tailing, and ligation of Illumina-compatible adapters (IDT, Inc) using the KAPA-Illumina library creation kit (KAPA biosystems). qPCR was used to determine the concentration of the libraries and were sequenced on the Illumina Hiseq (San Diego, CA) using $2 \times 150$ nt reads. 


\section{Metagenome assembly and annotation}

BBDuk adapter trimming (https://sourceforge.net/proje cts/bbmap/) was used to remove known Illumina adapters; parameters used were ktrim $=r$, minlen $=40$, minlenfraction $=0.6, \operatorname{mink}=11$, tbo, tpe, $k=23$, hdist $=1$, hdist $2=1, \mathrm{ftm}=5$. The reads were then processed using BBDuk filtering and trimming; parameters used were $\operatorname{maq}=8, \operatorname{maxns}=1$, minlen $=40$, minlenfraction $=0.6$, $k=27$, hdist $=1, \operatorname{trimq}=12, \mathrm{qtrim}=\mathrm{rl}$. At this stage, read ends were trimmed where quality values were less than 12. Read pairs containing more than three 'N', or with quality scores (before trimming) averaging less than 3 over the read, or length under $51 \mathrm{bp}$ after trimming, as well as reads matching Illumina artifact, spike-ins or PhiX were discarded. Remaining reads were mapped to a masked version of human HG19 with BBMap; parameters used were fast local minratio $=0.84$ maxindel $=6$ tipsearch $=4$ bw $=18$ bwr $=0.18$ usemodulo printunmappedcount idtag minhits $=1$, which discarded all hits over 93\% identity. Trimmed, screened, paired-end Illumina reads were assembled using megahit assembler [62] using a range of Kmers. Default settings for megahit parameters were used with options "-k-list $23,43,63,83,103,123$ ". The entire read set output from the previously described read pre-processing step were mapped to the final assembly and coverage information generated using SEAL [63]. Pfam (db v29) and KO (db IMG.nr-2016-7-22) were assigned using HMMER 3.1b2 (February 2015) and lastal 737+ as described in [64]. CAZymes were annotated following the steps described in [17] using BLAST+ [54] and HMMER.

\section{Binning, sample matching, and functional analysis}

Automated binning programs-MaxBin2 (v2.2.1) [65], MetaBat (v0.32.4) [66], and MyCC (v1) [67]-were evaluated with four metagenome samples prior to binning all metagenome samples. Effectiveness of binning was based on metrics provided by CheckM (v.1.0.7) [68] including average \% completeness of bins, average \% contamination of bins, average \% strain heterogeneity of bins, and the number of bins. Default parameters of each binning program were tested. Since the default minimum contig length of MetaBat was 2500 nucleotides, MaxBin2 and MyCC were also tested with this parameter. The "superspecific" MetaBat parameter setting was also tested. Mean completeness and \% of strain heterogeneity of MaxBin2, MyCC, and MetaBat were very similar (Additional file 5: Figure S2). A significant difference in contamination at $\alpha=0.05$ was detected by analysis of variance, and MaxBin2.2500 had the lowest average bin contamination (Additional file 5: Figure S2). Though a Tukey-Kramer test confirmed that the number of bins generated by MyCC exceeded that with MaxBin2.2500, the quality of bins was a higher priority for this study. Therefore, MaxBin2 with minimum contig length of 2500 nucleotides was used to bin all remaining metagenomes.

A customized Perl script, mapBin.pl (called MapBin for the remainder of this article), was developed to identify MaxBin2 genomic bins belonging to the same organisms but extracted from different metagenomes. Proteincoding genes were first predicted from the bins extracted from different metagenomes using FragGeneScan (v1.30) (with parameter-complete $=0$-train $=$ complete) [69]. Then predicted proteins were compared among every pair of bins from every metagenome using RAPSearch2 (v2.22) with default parameters [70]. Two bins were considered to be from the same organism if at least $70 \%$ of the protein identities were $>90 \%$. The final output of MapBin was a list indicating the most similar bins from one sample to another along with their proportion of highly similar protein matches. MapBin is available at https://sourceforge.net/projects/mapbin/. Simulated datasets described in [71] were used to test the effectiveness of MapBin, which successfully mapped three $20 \times$ coverage bins against $80 \times$ coverage bins as well as 30 low and medium complexity bins to high-complexity bins. The genome mapping accuracy was $100 \%$ (i.e., all mapped genomes were found to belong to the same organism). After extracting the completeness and contamination ratios using CheckM, we found that most of the bins with less than $10 \%$ contamination and greater than $50 \%$ completeness can be mapped very well (Additional file 6: Figure S3). Because MapBin also matched bins with much higher contamination and much lower completeness, we used thresholds of less than $20 \%$ contamination and greater than $40 \%$ completeness to reduce false-positive rates when evaluating genomic potential.

Pairwise comparisons of genomes binned from the switchgrass anaerobic digester metagenomes meeting the $70 \%$ protein match and $90 \%$ identity MapBin thresholds were combined into a single list. Pairwise comparisons where one or both bins had greater than $20 \%$ contamination or less than $40 \%$ completeness were removed in accordance with thresholds used in [68, 71], respectively. Remaining pairwise comparisons were imported into Cytoscape (v.3.4.0). Bins connected by less than three edges were separated, and only networks containing bins from more than three metagenomes were further analyzed. Genetic potential was evaluated with the remaining bins using genetic markers of interest including carbohydrate-active enzymes (CAZymes), markers with KEGG orthology (KOs) for xylose metabolism, and protein family (pfams) markers for syntrophy and methanogenesis, which were derived from [72] and MetaCyc. org [73] (Additional file 7: Table S4). Organisms were considered to encode a genetic marker if the majority 
of matching bins contained the marker. Taxonomy was assigned using CheckM [68], and manually updated if the average nucleotide identity \% calculated with both BLAST+ and MUMmer using the JSpecies webserver were greater than $95 \%$ [74].

\section{Results}

Microbiome establishment and performance at decreasing residence times

Anaerobic microbiomes derived from a digester inoculum were incubated at $55^{\circ} \mathrm{C}$ and fed semi-continuously with medium containing $30 \mathrm{~g} / \mathrm{L}$ mid-season harvested switchgrass to achieve residence times (RT) of 20, 10, 5 , and 3.3 days (Additional file 8: Table S5). Steady-state data for these 4 RTs studied are presented in Additional file 4: Table S3, Additional file 1: Figure S1 and Additional file 9: Figure S4, including biogas production rate and composition, fractional carbohydrate solubilization, volatile fatty acids (VFA) concentration, $\mathrm{pH}$ and mass and electron balances. Mass and electron balances (Additional file 4: Table S3 and Additional file 9: Figure S4) closed rather well between 84 and $106 \%$. Gas production increased with decreasing RT (Fig. 1a and Additional file 4: Table S3). The gas composition (Additional file 4: Table S3 and Additional file 1: Figure S1) was primarily methane and $\mathrm{CO}_{2}$. Progressing from $\mathrm{RT}=20$ days to 3.3 days, methane concentration decreased slightly from $50.5 \pm 1.0$ to $46.7 \pm 0.7 \%$ and $\mathrm{CO}_{2}$ increased from $42.6 \pm 2.2$ to $45.9 \pm 1.5 \%$. Minor amounts $(<10 \%)$ of $\mathrm{N}_{2}$ were detected likely because of the feeding and sampling process. A peak comigrating with $\mathrm{H}_{2}$ was detected, but was $\leq 0.1 \%$ of the fermentation gas mixture (100-fold lower than a $10 \% \mathrm{H}_{2}$ standard).

Time courses for production of VFA and $\mathrm{pH}$ are presented in Fig. 1b. VFA concentrations briefly exceeded $3 \mathrm{~g} / \mathrm{L}$ following inoculation, but were not detected after 30 days at $\mathrm{RT}=20$ days for all three reactors. Total VFAs were detectable at shorter RTs but never exceeded $0.5 \mathrm{~g} / \mathrm{L}$. Propionic acid was the main VFA accumulated, with acetic acid also observed; peaks with retention times corresponding to butyric, isobutyric and valeric acids were observed occasionally at concentrations near detection limits of $0.1 \mathrm{~g} / \mathrm{L}$ (see Additional file 4: Table S3). At $\mathrm{RT}=20$ days, $\mathrm{pH}$ stabilized at about 6.7 for R1, and 6.45 for R2 and R3. With decreasing RT, pH values for R2 and R3 were very similar, declining during cultivation as follows: $6.4-6.5$ at $\mathrm{RT}=20$ days, $6.3-6.4$ at $\mathrm{RT}=10$ days, 6.2 at $\mathrm{RT}=5$ days, and 6-6.2 at $\mathrm{RT}=3.3$ days (see Additional file 4: Table S3).

Carbohydrate solubilization reached steady state at each of the four RTs studied after a transient period of three RTs (Fig. 1c). Average steady-state fractional carbohydrate solubilization were $0.711 \pm 0.021$ at $\mathrm{RT}=20$ days (based on R1, R2 and R3), $0.654 \pm 0.023$ at $\mathrm{RT}=10$ days ( $\mathrm{R} 2$ and $\mathrm{R} 3$ ), $0.581 \pm 0.017$ at $\mathrm{RT}=5$ days ( $\mathrm{R} 2$ and $\mathrm{R} 3$ ), and $0.538 \pm 0.015$ at $\mathrm{RT}=3.3$ days ( $\mathrm{R} 2$ and $\mathrm{R} 3)$ as documented in Additional file 4: Table S3. Each of these mean values was significantly different from the values at the nearest residence times at $p=0.05$. Fractional xylan solubilization, $F C S_{x}$, is plotted as a function of glucan solubilization, $F C S_{g}$, for all reactors and all RTs in Fig. 2, and is described well by the linear equation $F C S_{x}=0.826 * F C S_{g}+0.114$.

Figure 3 plots the rate of carbohydrate solubilization, $r(\mathrm{~g} / \mathrm{L}$ day), as a function of the concentration of unutilized carbohydrate, $C$, both on a sugar monomer equivalent basis. The rate is observed to increase linearly with increasing concentration but to have a non-zero concentration intercept at zero rate. This behavior is consistent with kinetics being first order in accessible substrate, described by

$$
r=k\left(C-C_{0} f_{\mathrm{r}}\right)
$$

where $k$ is a rate constant, $C_{0}$ is the concentration of carbohydrate (cellulose and hemicellulose) entering the bioreactor $\left(C_{0}=17.3 \mathrm{~g} / \mathrm{L}\right)$ and $f_{\mathrm{r}}$ is the extrapolated fraction of entering carbohydrate that is recalcitrant at infinite residence time. Using data from both $\mathrm{R} 2$ and $\mathrm{R} 3$, the best fit value of $k$ was $0.717 \pm 0.068$ day $^{-1}$. The best fit value of $f_{\mathrm{r}}$ was $24.7 \pm 3.6 \%$.

\section{Microbiome composition in switchgrass digesters with decreasing residence times}

Bacteria and archaea in switchgrass digesters were monitored by the relative abundance of amplified partial $16 \mathrm{~S}$ rDNA genes. Figure 4 shows the phylum and taxon-level dynamics of bacteria and archaea with greater than $1 \%$ average abundance, and a PCoA graph provided in the

(See figure on next page.)

Fig. 1 Microbiome performance shown by time-course measurements. a Biogas production rate ( $\mathrm{mL} /$ day) vs. time. b Volatile fatty acids (VFA) concentration ( $\mathrm{g} / \mathrm{L}$ ) and $\mathrm{pH}$ vs. time. c Fractional carbohydrate solubilization vs. time. R1 was the control reactor and maintained at residence time $(R T)=20$ days throughout. R2 and R3 had decreasing RTs ( 20 days, 10 days, 5 days and 3.3 days) with each RT's period indicated by dashed black lines. Biogas production was recorded once per sampling interval (1/10th RT) and normalized to daily rate assuming constant rate during per interval. pH data was automatically acquired once per $5 \mathrm{~min}$ and subsampled to 3-4 data points per day to be shown in figure. FCS data were calculated based on total carbohydrates loaded and total residual carbohydrate in each sample. Acid concentration and FCS results are expressed as mean $\pm S D$ 


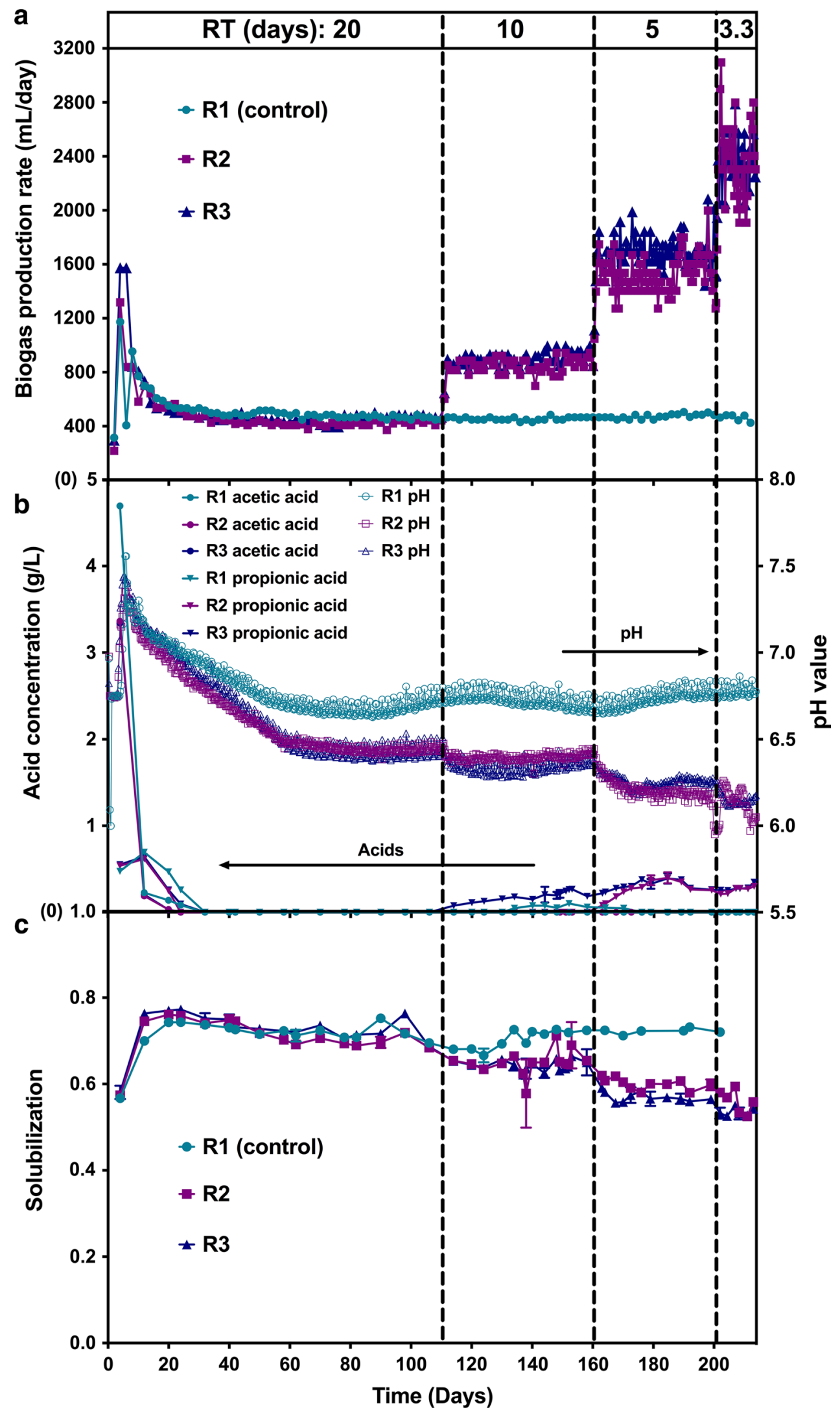




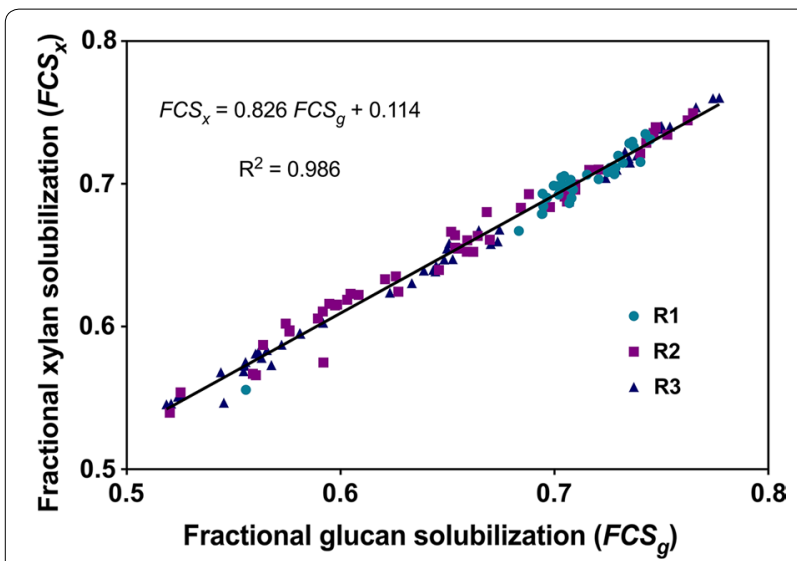

Fig. 2 Comparative solubilization of xylan and glucan. Data are for the same samples reported in Fig. 1. Best fit linear regression curve is shown as solid black line

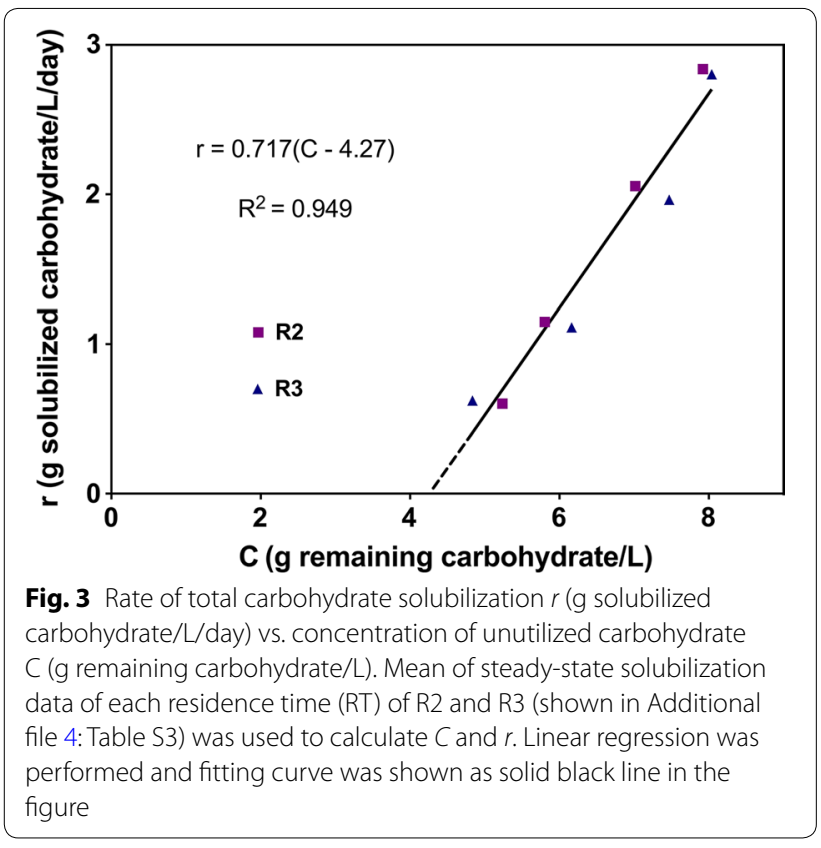

supplemental materials shows sample-level changes by weighted UniFrac (Additional file 10: Figure S5). At all levels, the population dynamics were very similar in experimental reactors R2 and R3. Firmicutes were the dominant phylum, increasing in inferred relative abundance from $54-96 \%$ as RT decreased. Thermotogae and Chloroflexi decreased with lower RT. Indeed, the most striking feature of the population dynamics was the decrease in a Thermotogaceae as RT was decreased from 20 to 3.3 days. This decline was more gradual in reactor 2 , but in reactor 3 , an abrupt drop in abundance was detected between 162 and 180 days of fermentation time when the RT was 5 days. Haloplasmataceae was more persistent than the other Chloroflexi in reactors 1 and 3 , but the highest relative abundance was observed in reactor 2 until the population declined sharply at $\mathrm{RT}=5$ days. Rapid decline of populations can occur when the dilution rate is greater than the growth rate, a phenomena termed washout [75]. Synergistetes (dominated by Acetomicrobium) and Euryarchaeota (dominated by Methanothermobacter) were relatively stable in all reactors. An organism from the RF3 clade of Tenericutes was also present in most samples with a higher relative abundance in reactor 2 than 1 or 3 . Uncultured representatives of the RF3 clade are like Mollicutes in that they ferment sugars into organic acids, but they also have the genetic potential to produce $\mathrm{H}_{2}$ from resulting reducing equivalents [76]. Proteobacteria, OP9, Nitrospirae, Gemmatimonadetes, Cyanobacteria, Acidobacteria, and other phyla each represented less than $1 \%$ of the average relative abundance of samples.

To gain a better understanding of the metabolic role of the most abundant species in the reactors, a phylogenetic tree was created (Additional file 11: Figure S6). Six of the operational taxonomic unit (OTU) sequences matched the partial 16S rDNA of previously isolated species. Isolates include thermophilic cellulose and hemicellulose fermenters, Clostridium clariflavum [77, 78] and Defluviitoga tunisiensis (Thermotogaceae in Fig. 4); a cellobiose and arabinose fermenter, Clostridium caenicola [79]; an Acetomicrobium (synergistetes in Fig. 4a) that ferments starch, glycerol, some monosaccharides and organic acids [80]; C. proteolyticus, previously shown to have high proteolytic activity in an office paper digester [81, 82], and a thermophilic hydrogenotrophic methanogen, either in the genus Methanothermobacter or Methanobacterium. Many of the other OTUs are related to bacteria known to ferment cellulose, cellobiose, xylan, xylose or a combination of these as well as other saccharides released

(See figure on next page.)

Fig. 4 Relative abundance of the bacterial and archaeal partial 16S rDNA genes with phylum (a) and taxon level resolution as low as genus (b) in switchgrass digesters. Fermentation periods are divided by days (D) and residence time ( $R$ ). The left and right columns are the inoculum ( () and substrate (S) profiles. Only taxa with average relative abundances of greater than $1 \%$ are indicated in the legend of $\mathbf{b}$. Steady state with respect to solubilization and gas composition was in general observed at times following change of the feed rate $\geq 3$ residence times as described elsewhere. Taxonomic profiles are presented both before and after this 3 residence time threshold. The number of taxonomic profiles made after this threshold for reactors R2 and R3, corresponding to the data to the right for each RT, were as follows: 3 for RT $=20$ days, 2 for RT $=10$ days, 3 for RT $=5$ days, 1 for $R T=3.3$ days 


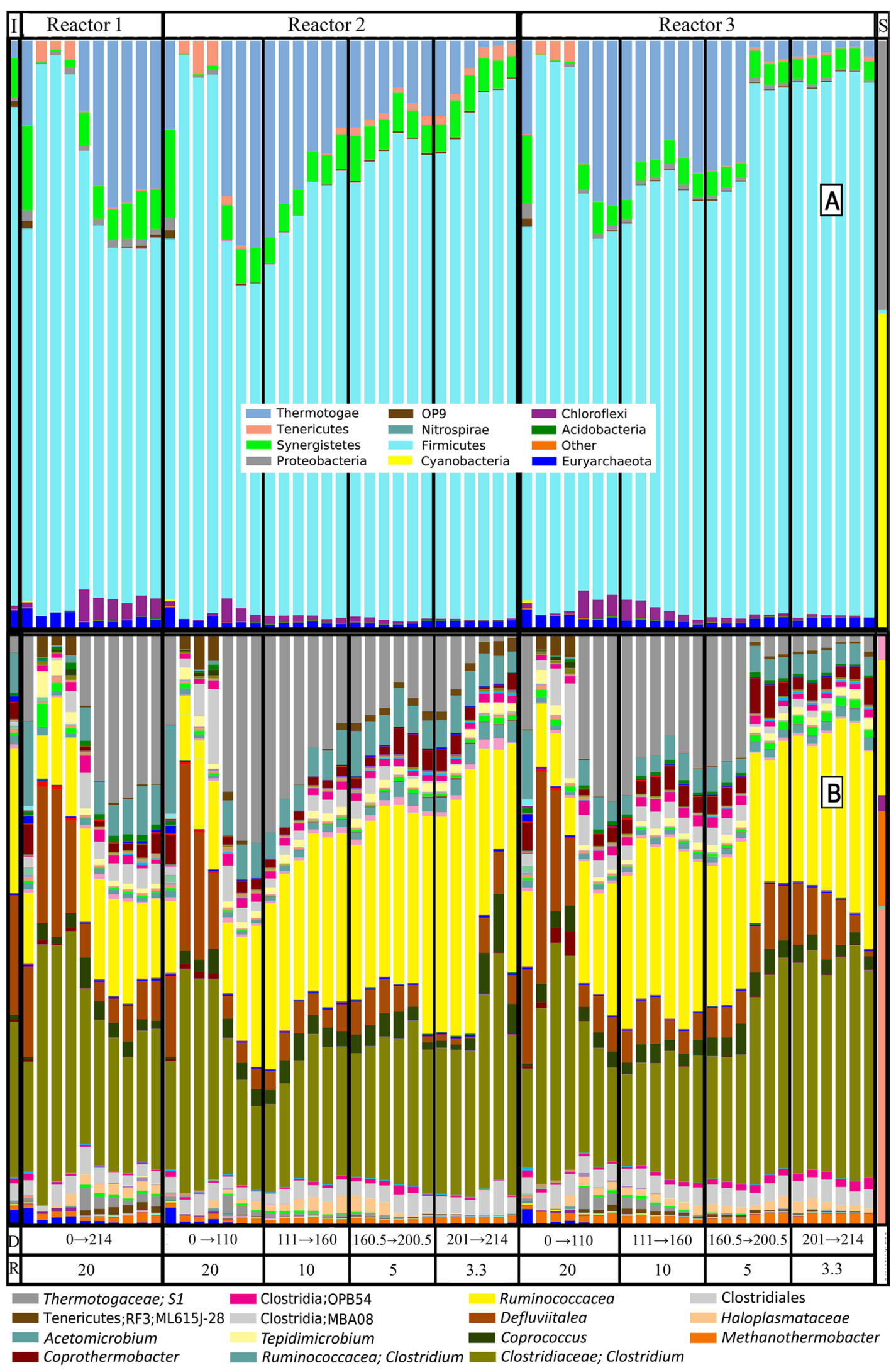


from plant biomass degradation into products including organic acids (acetate, propionate, and butyrate), $\mathrm{H}_{2}$ and $\mathrm{CO}_{2}$. One was also related to Clostridium ultunense, a syntrophic acetate oxidizer [83].

\section{Carbohydrate solubilization genetic potential of lignocellulose microbiome members}

Metagenomes were generated from samples taken from all three reactors at all RTs (15 metagenome total with an average of 226,652 sequences, 257,340,992 nucleotides, and 409,586 genes) and genomes were then binned to characterize the genetic potential of members of the switchgrass digester microbiome. Two hundred and seventy-five bins (35.5\%) were greater than $95 \%$ complete. Only 77 (9.9\%) were less than $40 \%$ complete and only $118(15.2 \%)$ contained greater than $20 \%$ contamination. Addition statistics for the metagenome assemblies and bins are provided in Additional file 12: Table S6. Figure 5 shows the average relative abundance of microbes in switchgrass digesters with average relative abundances greater than $0.1 \%$ and present in at least four of the fifteen metagenome samples. The abundance and taxonomy identified by metagenomics matched well with $16 \mathrm{~S}$ rDNA data, although there were understandable differences due to species-specific variation in scaffold retention and $16 \mathrm{~S}$ rDNA copy number, and marker-set verses single-gene-based taxonomic assignments, and inherent limitations for both methods. For example, metagenomics indicated that a cluster III Clostridium was the most abundant microbe at $\mathrm{RT}=3.3$ days with an average relative abundance of $15.3 \%$ and had the largest increase in relative abundance, up from $7.3 \%$ at $\mathrm{RT}=20$ days. Similarly, 16S rDNA dynamics show a Clostridium approximately doubling when comparing day 6 or $110(\mathrm{RT}=20)$ to day 214 (Fig. 4). The cluster III phylogenic group contains primarily cellulose-degrading Clostridium [78, 79], and members of this cluster have been observed to have higher growth rates than 3.3 days when grown in pure culture [3].

We quantified the total number of CAZymes for each member of the switchgrass digester microbiome (Fig. 5). CAZymes were further partitioned into categories: CAZyme families (to show diversity of functionality), quantity of glycoside hydrolases (since GHs are responsible for hydrolyzing the glycosidic bond of carbohydrates), quantity of modular CAZymes (because ancillary modules are often synergistic), and quantity of dockerins and cohesins (for detection of cellulosomes). Full list of modular CAZymes and individual modules including glycoside hydrolase, glycosyltransferase, polysaccharide lyases (which cleave glycoside linkages), and carbohydrate esterases detected in the metagenomes of each microbe are provided in Additional file 13: Table S7. C. clariflavum, a cluster III Clostridium (different from the most abundant organism in the switchgrass digesters at $\mathrm{RT}=3.3$ days), and $R$. thermocellum tended to dominate all of these categories (Fig. 5). Besides being the only cellulosomal bacteria in the community, they were also the only bacteria that encoded GH48 (Additional file 13: Table S7) which has been found to be critical for crystalline cellulose degradation in several bacteria [84]. C. clariflavum was approximately 7 times more abundant than the other two bacteria. The genome of the cellulosomal cluster III Clostridium had an average nucleotide identity of $75 \%$ for approximately $40 \%$ of the $R$. thermocellum ATCC27405 and DSM1313 genomes (BLAST+ method). Several of the modular enzymes of the cluster III Clostridium were similar in module arrangement and nucleotide identity to those encoded in $R$. thermocellum, but some were different including one that appeared to encode a novel xylanase with the modular arrangement GH11-CBM6GH10-CBM6-DOC (Additional file 13: Table S7). We also detected one organism from the order Clostridiales and one from the family Ruminococcaceae which had 16 and 13 dockerins, respectively, but no cohesins, an observation that has previously been reported in other studies $[17,85]$.

\section{Metabolic features of lignocellulose microbiome members In addition to cellulose utilization, the metabolic guild structure of the community was examined by searching bins for conserved markers and pathways involved in anaerobic digestion of organic matter to methane. Xylose catabolism, methanogenesis (acetoclastic and hydrog- enotrophic), and syntrophic pathways for acetate, pro- pionate and butyrate utilization were assessed (Fig. 5).}

\footnotetext{
(See figure on next page.)

Fig. 5 Switchgrass digester microbial community with CAZymes profiles and key metabolic pathways. Each microbe listed was found in at least four of fifteen metagenome samples taken from three reactors operating at residence times (RT) of 20, 10, 5, and 3.3 days. Taxonomy was assigned using CheckM; species were manually assigned if its average nucleotide identity was greater than 95\% the type strain genome. Microbes were sorted by average relative abundance at the 3.3-day RT. Average relative abundance was not determined (ND) for microbes whose metagenome bins were less than $40 \%$ complete or had greater than $20 \%$ contamination. Darker green colors indicate higher counts of CAZyme markers. Marker sets used to evaluate metabolic potential were taken from MetaCyc.org and Worm et al. [72]. Complete marker sets are indicated by green pie graphs, while incomplete marker sets with greater than $70 \%$ completeness are indicated by red and blue pie graphs, where red indicates the percentage of missing markers
} 


\section{Taxonomy}

g_Clostridium_3

$s$ _Clostridium_clariflavum

o__Clostridiales

s_Coprothermobacter_proteolyticus

g_Clostridium_3

s_Defluviitoga_tunisiensis

o_Clostridiales

c_Bacilli

c_Mollicutes

g_Clostridium_3

o__Thermoanaerobacterales

$s$ Ruminiclostridium thermocellum

o Clostridiales

$s$ __Methanothermobacter_thermautotrophicus

o Clostridiales

g_Clostridium_3

o__Clostridiales

p_Firmicutes

o_Clostridiales

o__Thermoanaerobacterales

p_Firmicutes

s_Methanosarcina_thermophila

s_Methanobacterium_sp._MB1

g_Clostridium_3

o__Clostridiales

p__Firmicutes

o_Clostridiales

- Clostridiales

p_Firmicutes

$f$ _Ruminococcaceae

g_thermodesulfovibrio

o__Clostridiales

o Acidobacteriales

$f$ Ruminococcaceae

o__Clostridiales

f_Rhodocyclaceae

k_Bacteria

o_Clostridiales

$f$ Syntrophomonadaceae

$f$ Synergistaceae

g_Clostridium_3

p_Firmicutes

c__Mollicutes

$\mathrm{p}$ _Chloroflexi

p_Chloroflexi

g_Clostridium_3

p_Chloroflexi

o__Clostridiales_3

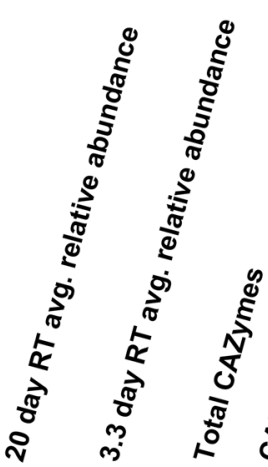

范
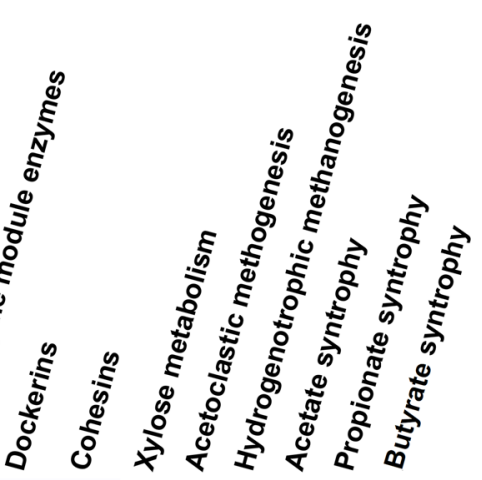

$\begin{array}{lllllllll}7.3 \% & 15.3 \% & 75 & 43 & 37 & 5 & 0 & 0 & 0\end{array}$

\begin{tabular}{ll|l|l|l|l|l|l}
$8.2 \%$ & $10.8 \%$ & 275 & 74 & 64 & 58 & 60 & 21 \\
\hline
\end{tabular}

$\begin{array}{llllllll}5.3 \% & 5.5 \% & 76 & 41 & 49 & 3 & 0 & 0\end{array}$

$\begin{array}{llllllll}4.8 \% & 4.8 \% & 27 & 13 & 6 & 0 & 0 & 0\end{array}$

$\begin{array}{lllllllll}4.4 \% & 2.7 \% & 75 & 43 & 31 & 6 & 0 & 0 & 0\end{array}$

$\begin{array}{llllllll}\text { ND } & 2.5 \% & 85 & 41 & 33 & 5 & 0 & 0\end{array}$

$\begin{array}{llllllll}9.3 \% & 2.3 \% & 93 & 39 & 21 & 12 & 1 & 3\end{array}$

$\begin{array}{llllllll}2.2 \% & 1.7 \% & 91 & 42 & 49 & 7 & 0 & 0\end{array}$

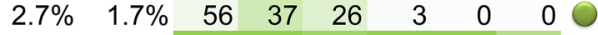

$\begin{array}{rlllllll}1.7 \% & 1.6 \% & 319 & 78 & 80 & 72 & 68 & 14\end{array}$

$\begin{array}{rrrrrrrr}0.8 \% & 1.5 \% & 102 & 52 & 70 & 8 & 0 & 0\end{array}$

$\begin{array}{rrrrrrrr}1.2 \% & 1.4 \% & 283 & 74 & 67 & 63 & 64 & 15\end{array}$

\begin{tabular}{lll|l|l|l|l|l|}
$1.9 \%$ & $1.4 \%$ & 128 & 47 & 65 & 14 & 2 & 1 \\
\hline
\end{tabular}

$\begin{array}{llllllll}2.0 \% & 1.3 \% & 22 & 6 & 0 & 1 & 0 & 0\end{array}$

$\begin{array}{rrrrrrrr}1.5 \% & 1.0 \% & 116 & 41 & 56 & 14 & 2 & 2\end{array}$

$\begin{array}{llllllll}0.7 \% & 0.9 \% & 139 & 66 & 81 & 9 & 2 & 0\end{array}$

$\begin{array}{llllllll}1.3 \% & 0.9 \% & 30 & 15 & 5 & 3 & 0 & 0\end{array}$

$\begin{array}{llllllll}1.3 \% & 0.7 \% & 127 & 42 & 22 & 6 & 0 & 0\end{array}$

$\begin{array}{rlllllll}0.7 \% & 0.6 \% & 89 & 34 & 29 & 10 & 16 & 0\end{array}$

$\begin{array}{llllllll}0.2 \% & 0.6 \% & 86 & 48 & 49 & 7 & 0 & 0\end{array}$

$\begin{array}{llllllll}0.2 \% & 0.5 \% & 84 & 38 & 28 & 6 & 0 & 0\end{array}$

$\begin{array}{rlllllll}1.5 \% & 0.5 \% & 51 & 16 & 12 & 1 & 0 & 0\end{array}$

$\begin{array}{rlrrrrrr}1.6 \% & 0.4 \% & 47 & 5 & 0 & 2 & 0 & 0\end{array}$

$\begin{array}{llllllll}0.2 \% & 0.4 \% & 102 & 41 & 36 & 10 & 0 & 0\end{array}$

$\begin{array}{llllllllll}0.7 \% & 0.4 \% & 219 & 61 & 91 & 22 & 0 & 0 & 0\end{array}$

$\begin{array}{llllllll}0.8 \% & 0.4 \% & 153 & 50 & 68 & 26 & 5 & 1\end{array}$

$\begin{array}{llllllll}0.4 \% & 0.4 \% & 135 & 45 & 56 & 20 & 0 & 0\end{array}$

$\begin{array}{llllllll}0.5 \% & 0.4 \% & 31 & 17 & 6 & 3 & 0 & 0\end{array}$

\begin{tabular}{rll|l|l|llll}
$0.3 \%$ & $0.4 \%$ & 157 & 62 & 69 & 14 & 0 & 0 & 0
\end{tabular}

$\begin{array}{lllllllll}0.4 \% & 0.3 \% & 96 & 46 & 57 & 3 & 13 & 0 & 0\end{array}$

$\begin{array}{llllllll}0.9 \% & 0.3 \% & 70 & 29 & 14 & 4 & 0 & 0\end{array}$

$\begin{array}{lllllllll}0.6 \% & 0.3 \% & 86 & 37 & 44 & 8 & 1 & 0 & 0\end{array}$

$\begin{array}{rllllllll}0.5 \% & 0.2 \% & 211 & 70 & 72 & 12 & 1 & 0\end{array}$

$\begin{array}{llllllll}0.5 \% & 0.2 \% & 35 & 25 & 11 & 2 & 0 & 0\end{array}$

$\begin{array}{llllllll}0.3 \% & 0.2 \% & 30 & 18 & 9 & 1 & 0 & 0\end{array}$

$\begin{array}{llllllll}0.6 \% & 0.2 \% & 48 & 20 & 12 & 2 & 0 & 0\end{array}$

$\begin{array}{llllllll}0.4 \% & 0.2 \% & 53 & 33 & 20 & 2 & 0 & 0\end{array}$

$\begin{array}{llllllll}0.3 \% & 0.2 \% & 86 & 48 & 49 & 4 & 0 & 0\end{array}$

$\begin{array}{llllllll}0.4 \% & 0.1 \% & 47 & 23 & 10 & 5 & 1 & 0\end{array}$

$\begin{array}{llllllll}3.2 \% & \text { ND } & 36 & 19 & 8 & 2 & 0 & 0\end{array}$

\begin{tabular}{ll|l|lllll}
$2.5 \%$ & ND & 121 & 50 & 66 & 9 & 2 & 0
\end{tabular}

$\begin{array}{rllllllll}2.5 \% & \text { ND } & 158 & 55 & 77 & 21 & 0 & 0\end{array}$

$\begin{array}{llllllll}1.6 \% & \text { ND } & 85 & 26 & 11 & 4 & 1 & 0\end{array}$

$\begin{array}{llllllll}1.4 \% & \text { ND } & 212 & 58 & 56 & 15 & 0 & 0\end{array}$

$0.9 \% \quad$ ND $\quad 170 \quad 42 \quad 42 \quad 12 \quad 0 \quad 120$

$\begin{array}{llllllll}0.8 \% & \text { ND } & 100 & 42 & 56 & 8 & 1 & 1\end{array}$

$\begin{array}{llllllll}0.7 \% & \text { ND } & 186 & 57 & 67 & 15 & 0 & 0\end{array}$

$\begin{array}{llllllll}0.7 \% & \text { ND } & 43 & 19 & 11 & 5 & 0 & 0\end{array}$ 
Bins containing pfam domains corresponding to xylose isomerase (pfam01261) and xylulokinase (pfam00370, pfam02782) were widespread throughout the community and notably, in the most abundant species including Clostridium clariflavum. Strains of C. clariflavum have been shown to utilize both hexose and pentose sugars, a feature that distinguishes the organism from $R$. thermocellum [77]. While saccharolytic, fermentative bacteria dominated the microbiome, short chain fatty acids did not accumulate at the 20-day RT and remained below $1 \mathrm{~g} / \mathrm{L}$ during the 10, 5 and 3.3-day RTs (Fig. 1) suggesting obligate and/or facultative syntrophic interactions were enabled by the presence of methanogens. In thermophilic systems, acetate removal via syntrophic oxidation has been observed to be favored over uptake by acetoclastic methanogens [86] and sequences associated most closely with $M$. thermautotrophicus showed the highest abundance in both the 20-day and 3.3-day RTs. Acetate oxidation occurs via the Wood-Ljungdahl (reductive acetyl-CoA) pathway operating in the reverse direction [72]. Therefore, pfam domains representing the pathway including pfam01268 for formyltetrahydrofolate synthetase, an essential function and marker gene [87], were used to query bins for the potential for acetate oxidation. Four bacteria genomes contained near-complete pathways including pfam01268 which were associated with Thermodesulfovibrio spp. and Syntrophomonadaceae (Fig. 5). Evidence for syntrophic propionate utilization was more abundant, especially for the 20-day RT, as indicated by the presence of genes with pfam domains that are included in the methylmalonyl-CoA pathway and periplasmic formate dehydrogenase which are key functions for propionate oxidation in Syntrophobacter fumaroxidans [72]. Reducing the RT to 3.3 days apparently washed out a portion on the predicted propionatedependent syntrophs, especially organisms belonging to the phylum Chloroflexi [88]. Likewise, potential butyratedependent syntrophic organisms represented a minor, yet diverse component of the microbiome. Based on comparative genomic and functional proteomic studies, the essential genes/enzymes for butyrate oxidation in Syntrophomonas wolfei have been described [72, 89]. The binned genomes were searched for conserved pfam domains involved in butyrate and formate metabolism with organisms associated with Syntrophomonadaceae displaying a full set of predicted conserved genes necessary for syntrophic growth. Genomic bins associated with Rhodocyclaceae and Thermodesulfovibrio spp. also contained extracytoplasmic FDH and FDH accessory proteins (pfam04216) which are indicative of butyrate syntrophy. A full list of pfams identified for each microbe are provided in Additional file 7: Table S4.

\section{Discussion}

Stable, thermophilic, lignocellulose-fermenting microbiomes were established at residence times (RT) from 20 to 3.3 days. Consistent with the objective of establishing a well-controlled system for studying lignocellulose solubilization, we developed a feeding protocol that involved replacing one-tenth of the reactor volume at regular time intervals with a consistent lignocellulose feedstock. Many other studies use different feeding protocols as determined by their aims and circumstancesincluding batch, fully continuous, various lignocellulosic substrates and water contents, and time-varying substrates (e.g., any actual waste). As frequently noted in the literature $[90,91]$, inter-study comparisons and generalized conclusions are challenging because of the large number of operational variables that impact the composition and performance of anaerobic digesters and similar systems. Acknowledging these factors, the first-order rate constant we observed for carbohydrate solubilization $\left(0.53\right.$ day $\left.^{-1}\right)$ is larger, and 3.3-day RT shorter than most reports in the literature for methanogenic digestion of lignocellulosic feedstocks $[9,10]$.

Anaerobic microbiomes fed mid-season switchgrass reached steady-state at each of the four RTs examined as indicated by biogas production and composition, $\mathrm{pH}$, organic acid levels, and fractional carbohydrate solubilization. As compared to the intermittent feeding strategy used in our studies, data interpretation is somewhat more straight forward for reactors fed in a fully continuous manner. However, fully continuous feeding becomes infeasible at high solid concentration, theoretical frameworks for considering intermittently fed reactors are available, and such frameworks suggest that differences between fully continuous and intermittent feeding are not large as long as the fraction of culture volume replaced per feeding is relatively small [92].

Most reports of thermophilic, anaerobic, methanogenic digestion of lignocellulose and related materials are at RT $>3.3$ days as observed in our study. For example, Vanwonterghem et al. [13] observed that over 70\% of solubilized alpha cellulose was converted to VFAs at $55{ }^{\circ} \mathrm{C}$ and $\mathrm{RT}=4$ days. The shortest $\mathrm{RT}$ reported by Yilmaz et al. [93] for digestion of papermill wastewater at $55{ }^{\circ} \mathrm{C}$ was 6 days. Kim et al. [15] in 2006 digesting food waste at $55{ }^{\circ} \mathrm{C}$ observed reduced methane yield and had trouble maintaining stability as $\mathrm{RT}$ was reduced from 10 to 8 days. Liu et al. [14] also reported reduced methane yield for digestion of swine manure and corn stover at $50{ }^{\circ} \mathrm{C}$ when RT was lowered from 10 to 5 days. We speculate that our observation of stable methanogenesis at short residence times may be due to the well-controlled and frequent feeding regime employed. 
As reported by Van Soest [94] and Richard [95], kinetics were observed to be first order for the remaining accessible carbohydrate. The inferred concentration of recalcitrant carbohydrate, corresponding to the zerorate intercept in Fig. 3, was $24.7 \%$ of the carbohydrate contained in the substrate prior to fermentation. We expect that fully senescent switchgrass would have a yet higher fraction of recalcitrant carbohydrate compared to mid-season switchgrass as has been observed in pure culture studies with $R$. thermocellum [96, 97]. Modeling the rate of lignocellulose solubilization as first order in carbohydrate is common in studies of both anaerobic digesters and pure cultures $[3,10]$. Our results suggest that accounting for recalcitrant carbohydrate can be a useful refinement of descriptive rate laws for lignocellulose solubilization, and that the fraction of recalcitrant carbohydrate may be an informative comparative metric for various microbial systems and feedstocks. Glucan and xylan solubilization were observed to be linearly correlated, consistent with the results of Paye et al. [4].

The three most abundant cellulolytic microorganisms were $C$. clariflavum, $R$. thermocellum, and an uncultured cluster III Clostridium. C. clariflavum was approximately seven times more prevalent than the other two predicted cellulosomal bacteria at all RTs, and differed in that it contained markers for xylose metabolism (Fig. 5). All three were found to encode similar overall numbers of CAZymes, CAZyme families, GHs, and modular enzymes as well as dockerin and cohesin modules, indicative of cellulosomes (Fig. 5). Thus, the number, diversity, and architecture of CAZymes were not a particularly good predictor of quantitative abundance.

Defluviitoga tunisiensis had the most dramatic population shift of any species in switchgrass digesters when RT was decreased from 20 to 3.3 days (Fig. 4). At the end of the incubation period with $\mathrm{RT}=20$ days, the relative abundance for $D$. tunisiensis exceeded that of two highly abundant Clostridium species, an uncultured cluster III Clostridium and C. clariflavum (Fig. 4). However, the average relative abundance of $D$. tunisiensis decreased to $2.5 \%$ at $\mathrm{RT}=3.3$ days (Figs. 4,5 ), while these two Clostridium species increased in abundance to $15.3 \%$ and $10.8 \%$, respectively. Separate previous studies have indicated a high abundance of Thermotogae in thermophilic biogas reactors operating at high RTs of 30 days [88] and 19.8 days [98] and low abundance of Thermotogae in biogas reactors operating at RTs of 4 and 3 days [12] and 1 day [99]. To our knowledge, this study is the first to capture a dynamic shift in relative abundance of a Thermotogae. D. tunisiensis is a primary fermenter capable of growing on microcrystalline cellulose [100], but the genome sequence of the L3 strain only encoded a GH5 cellulase [101]. The D. tunisiensis strain identified in this study encoded a GH5 cellulase but did not encode a GH48 cellulase (Additional file 13: Table S7), which was previously found to be an absolute requirement for pure culture crystalline cellulose hydrolysis in the genus Caldicellulosiruptor [102]. The relationship between certain specific CAZyme markers such as GH48, thought to be indicative of strong cellulolytic activity, other metabolic markers (e.g., xylose utilization) and to the success individual members and the overall lignocellulosic microbiome requires further quantitative study.

Genomic science opens unprecedented windows into the composition and function of microbiomes, including but not limited to microbiomes based on lignocellulosic substrates. In the context of gaining insights into lignocellulose solubilization based on microbiome studies, we see a need and opportunity for hypothesis testing based on melding bioinformatic and comparative solubilization data obtained under controlled conditions and in particular with defined microbial communities. It is also important that community standards are developed to allow microbiome comparisons between different systems and for future more detailed mechanistic insights. There is also a place for cultured lignocellulosic microbiome representatives complete with genome sequences to test certain hypotheses, such as described recently for the Hungate 1000 project which is a catalogue of reference genomes from the rumen microbiome [103]. We hope that the methods, systems, and genomic resources and results presented here will provide a foundation for such studies.

\section{Conclusions}

In this study, we established stable, anaerobic, switchgrassfermenting, methanogenic enrichment cultures at various residence times at $55^{\circ} \mathrm{C}$. Minimal accumulation of organic acids was observed for all RTs. Fractional carbohydrate solubilization was $0.711,0.654,0.581$ and 0.538 at $\mathrm{RT}=20$, 10,5 and 3.3 days, respectively. The 3.3 day RT is among the shortest RT reported for stable thermophilic, methanogenic digestion of a lignocellulosic feedstock. Features of the microbiomes were documented, including descriptive rate laws, and relative solubilization of cellulose and hemicellulose. 16S rDNA phylotyping and metagenomic analyses were conducted to infer functional roles in the switchgrass to biogas conversion to the various microbial taxa and to characterize the microbial communities present at various residence times. C. clariflavum, $R$. thermocellum, and an uncultured cluster III Clostridium were the most abundant putative cellulolytic microbes present. Although these three microbes manifested similar numbers, diversities, and architectures of CAZymes, C. clariflavum was the most abundant by sevenfold. 


\section{Additional files}

Additional file 1: Figure S1. Biogas composition vs. time. R1 was the control reactor and maintained at residence time $(R T)=20$ days throughout. R2 and R3 had decreasing RTs (20 days, 10 days, 5 days and 3.3 days) with each RT's period indicated by solid black lines. Contents of $\mathrm{CH}_{4}$ and $\mathrm{CO}_{2}$ were expressed on fractional basis.

Additional file 2: Table S1. ANOVA of effects of residence time (RT) and anaerobic/aerobic sampling method on total carbohydrate solubilization.

Additional file 3: Table S2. ANOVA of effects of residence time (RT) and anaerobic/aerobic sampling method on $\mathrm{CH}_{4}$ content.

Additional file 4: Table S3. Steady State Data Summary. Results are expressed as mean $\pm \mathrm{SD}$.

Additional file 5: Figure S2. Comparison of statistics generated from four metagenomes from reactor R3 that were binned with MaxBin2, MyCC, and MetaBat programs. Default parameters were tested. Since the default minimum contig length of MetaBat was 2500 nucleotides, MaxBin and MyCC were also tested with this parameter. The "superspecific" MetaBat parameter settings were also tested. Error bars indicate the standard deviation of averaged binning statistics of the four metagenomes. Significantly different means were identified by ANOVA at an $a=0.05$ for the $\%$ contamination and number of bins. However, a Tukey-Kramer post hoc test only identified a significant difference in the mean number of bins for MyCC compared to MaxBin2.2500.

Additional file 6: Figure S3. MapBin. Plot indicating the completeness and contamination distribution of bins that can or cannot be mapped. $X$-axis indicates completeness ratio (\%) while Y-axis means contamination ratio (\%). Black dots are bins that can be mapped; gray ones are bins that cannot.

Additional file 7: Table S4. Genetic markers of interest including carbohydrate-active enzymes (CAZymes), markers with KEGG orthology (KOs) for xylose metabolism, and protein families (pfams) markers for syntrophy and methanogenesis, which were derived from [72] and MetaCyc.org.

Additional file 8: Table S5. Reactor operating length and steady state length at each residence time (RT). R1 was the control reactor always running at $R T=20$ days and $R 2 \& R 3$ had decreasing RTs.

Additional file 9: Figure S4. a. COD recovery vs. time; b. Mass recovery vs. time. R1 was the control reactor and maintained at residence time $(R T)=20$ days throughout. R2 and R3 had decreasing RTs (20 days, 10 days, 5 days and 3.3 days) with each RT's period indicated by solid black lines. Results were expressed as mean \pm SD.

Additional file 10: Figure S5. PCoA plot of sample phylogenetic distance. Phylogenetic distance of samples represented by weighted UniFrac values. Residence time (RT) is represented by different colors. Reactor 1 (A1) samples are twice the size of samples for reactors 2 (A2) and 3 (A3) reactors. Samples are labeled with [reactor]_[day].

Additional file 11: Figure S6. Maximum likelihood phylogenetic tree of the most abundant operational taxonomic units in the switchgrass digesters (bold numbers), which when summed together account for greater than $80 \%$ of the average relative abundance. Numbers given to OTUs only allude to the abundance of the OTUs in one of the 61 switchgrass digester samples. Numbers adjacent to branches show bootstrap supports that were greater than 50\%. The scale bar and numbers below the branchbreaks indicate the number of nucleotide substitutions per position in the V4 region of the 165 rDNA gene sequences.

Additional file 12: Table S6. Addition statistics for the metagenome assemblies and bins.

Additional file 13: Table S7. Total CAZyme domain counts normalized by number of matching bins for a species and modular CAZymes detected in the matching bins for each species. Taxon are ordered as seen in Fig. 5.

\section{Abbreviations}

CAZymes: carbohydrate-active enzymes; COD: chemical oxygen demand; GTR: generalized time reversible; ND: not determined; NTA: nitrilotriacetic acid; OTU: operational taxonomic unit; RT: residence time; VFA: volatile fatty acids.

\section{Authors' contributions}

$X L, X S, E K H, T L R$ and LRL designed the fermentation experiments and analytical methods for fermentation samples. XL, LT, EKH performed the fermentation experiments and sample analysis. JMW, JGE and SDB designed and performed 16s rDNA analysis and metagenomic analysis. Y-WW wrote MapBin and assisted with metagenomic analysis. VL and BH annotated CAZymes in metagenomes. DMK and ZKY generated DNA and 165 rDNA reads from culture samples. MP assisted with 165 rDNA analysis. XL and JMW wrote the manuscript. EKH, TLR, JGE, SDB and LRL revised the manuscript. $X L$ and JMW contributed equally to this study. All authors read and approved the final manuscript.

\section{Author details}

${ }^{1}$ Thayer School of Engineering, Dartmouth College, Hanover, NH 03755, USA. 2 BioEnergy Sciences Center, Oak Ridge, TN 37830, USA. ${ }^{3}$ Biosciences Division, Oak Ridge National Laboratory, Oak Ridge, TN 37830, USA. ${ }^{4}$ Graduate Institute of Biomedical Informatics, College of Medical Science and Technology, Taipei Medical University, Taipei 106, Taiwan. ${ }^{5}$ CNRS, UMR 7257, Aix-Marseille University, 13288 Marseille, France. ${ }^{6}$ INRA, USC 1408 AFMB, 13288 Marseille, France. ${ }^{7}$ Department of Biological Sciences, King Abdulaziz University, Jeddah, Saudi Arabia. ${ }^{8}$ Department of Agricultural and Biological Engineering, The Pennsylvania State University, University Park, State College, PA 16802, USA. ${ }^{9}$ Present Address: LanzaTech, Inc., Skokie, IL 60077, USA.

\section{Acknowledgements}

We thank the Vermont Technical College anaerobic digester team for providing samples for the initial inocula and Marvin Hall and Kay DiMarco from the Pennsylvania State University for partially preparing the feedstock for this study. We thank Sean J.L. Murphy and Robert S. Worthen for help in reactor maintenance. Chris Schadt (Bioscience Division, Oak Ridge National Laboratory) provided instructional support for building a phylogenetic tree in Geneious and Michael Robeson (Interstitial Genomics, LLC) provided scripts and consultation for $16 \mathrm{~S}$ amplicon data processing and analysis. Metagenomic data were generated and annotated by the US Department of Energy Joint Genome Institute, a DOE Office of Science User Facility, is supported by the Office of Science of the US Department of Energy under Contract no. DE-AC02-05CH11231.

This manuscript has been authored by Dartmouth College and UT-Battelle, LLC, under contract DE-AC05-000R22725 with the US Department of Energy (DOE). The US government retains and the publisher, by accepting the article for publication, acknowledges that the US government retains a nonexclusive, paid-up, irrevocable, worldwide license to publish or reproduce the published form of this manuscript, or allow others to do so, for US government purposes. DOE will provide public access to these results of federally sponsored research in accordance with the DOE Public Access Plan (http://energy.gov/downl oads/doe-public-access-plan).

\section{Competing interests}

The authors declare that they have no competing interests.

\section{Availability of data and materials}

All data generated or analyzed during this study are included in this published article and its Additional files.

\section{Consent for publication}

Not applicable.

\section{Ethics approval and consent to participate}

Not applicable.

\section{Funding}

This research was sponsored primarily by the BioEnergy Science Center, a US Department of Energy Bioenergy Research Center supported by the Office of Biological and Environmental Research (Grant No. DE-AC05-00OR22725) in the DOE Office of Science. Oak Ridge National Laboratory is managed by 
UT-Battelle, LLC, for the US DOE under contract DE-AC05-00OR22725. This work was also supported by the Biomass Research and Development Initiative (Grant No. 2016-10008-25319) from the National Institute of Food and Agriculture, US Department of Agriculture.

\section{Publisher's Note}

Springer Nature remains neutral with regard to jurisdictional claims in published maps and institutional affiliations.

Received: 13 April 2018 Accepted: 27 August 2018

Published online: 06 September 2018

\section{References}

1. Sawatdeenarunat C, Surendra KC, Takara D, Oechsner H, Khanal SK. Anaerobic digestion of lignocellulosic biomass: challenges and opportunities. Bioresour Technol. 2015;178:178-86. https://doi.org/10.1016/j. biortech.2014.09.103.

2. Podkaminer K, Lin Z. Analyzing the impacts of a biogas-to-electricity purchase incentive on electric vehicle deployment with the MA3T vehicle choice model. Washington, D.C: US Department of Energy; 2017.

3. Lynd LR, Weimer PJ, van ZyI WH, Pretorius IS. Microbial cellulose utilization: fundamentals and biotechnology. Microbiol Mol Biol Rev. 2002;66:506-77. http://www.ncbi.n/m.nih.gov/pubmed/12209002. Accessed 23 Dec 2016.

4. Paye JMD, Guseva A, Hammer SK, Gjersing E, Davis MF, Davison BH, et al. Biological lignocellulose solubilization: comparative evaluation of biocatalysts and enhancement via cotreatment. Biotechnol Biofuels. 2016;9:1-13.

5. Li Y, Park SY, Zhu J. Solid-state anaerobic digestion for methane production from organic waste. Renew Sustain Energy Rev. 2011;15:821-6. https://doi.org/10.1016/j.rser.2010.07.042.

6. Pohl M, Mumme J, Heeg K, Nettmann E. Thermo- and mesophilic anaerobic digestion of wheat straw by the upflow anaerobic solidstate (UASS) process. Bioresour Technol. 2012;124:321-7. https://doi org/10.1016/j.biortech.2012.08.063.

7. Sheets JP, Ge X, Li Y. Effect of limited air exposure and comparative performance between thermophilic and mesophilic solid-state anaerobic digestion of switchgrass. Bioresour Technol. 2015;180:296-303.

8. Holwerda EK, Lynd LR. Testing alternative kinetic models for utilization of crystalline cellulose (Avicel) by batch cultures of Clostridium thermocellum. Biotechnol Bioeng. 2013;110:2389-94.

9. Mata-Alvarez J, Macé S, Llabrés P. Anaerobic digestion of organic solid wastes. An overview of research achievements and perspectives. Bioresour Technol. 2000;74:3-16. https://doi.org/10.1016/S0960 -8524(00)00023-7.

10. Pavlostathis SG, Giraldo-Gomez E. Kinetics of anaerobic treatment: a critical review. Crit Rev Environ Control. 1991;21:411-90. https://doi. org/10.1080/10643389109388424.

11. Zahedi S, Sales D, Romero LI, Solera R. Optimisation of single-phase drythermophilic anaerobic digestion under high organic loading rates of industrial municipal solid waste: population dynamics. Bioresour Technol. 2013;146:109-17. https://doi.org/10.1016/j.biortech.2013.07.055.

12. Ho D, Jensen P, Batstone D. Effects of temperature and hydraulic retention time on acetotrophic pathways and performance in high-rate sludge digestion. Environ Sci Technol. 2014;48:6468-76.

13. Vanwonterghem I, Jensen PD, Rabaey K, Tyson GW. Temperature and solids retention time control microbial population dynamics and volatile fatty acid production in replicated anaerobic digesters. Sci Rep. 2015;5:8496. https://doi.org/10.1038/srep08496.

14. Liu Z. Thermophilic anaerobic co-digestion of swine manure with corn stover for biogas production. North Carolina State University; 2017. https://repository.lib.ncsu.edu/bitstream/handle/1840.20/33628/etd. pdf? sequence $=1$. Accessed 4 Apr 2018.

15. Kim JK, Oh BR, Chun YN, Kim SW. Effects of temperature and hydraulic retention time on anaerobic digestion of food waste. J Biosci Bioeng. 2006;102:328-32. https://doi.org/10.1263/JBB.102.328.
16. Pohl M, Heeg K, Mumme J. Anaerobic digestion of wheat strawperformance of continuous solid-state digestion. Bioresour Technol. 2013;146:408-15. https://doi.org/10.1016/j.biortech.2013.07.101.

17. Svartström O, Alneberg J, Terrapon N, Lombard V, de Bruijn I, Malmsten $J$, et al. Ninety-nine de novo assembled genomes from the moose (Alces alces) rumen microbiome provide new insights into microbial plant biomass degradation. ISME J. 2017;11:2538-2551.

18. Morrison M, Pope PB, Denman SE, McSweeney CS. Plant biomass degradation by gut microbiomes: more of the same or something new? Curr Opin Biotechnol. 2009;20:358-63.

19. Güllert S, Fischer MA, Turaev D, Noebauer B, Ilmberger N, Wemheuer B, et al. Deep metagenome and metatranscriptome analyses of microbial communities affiliated with an industrial biogas fermenter, a cow rumen, and elephant feces reveal major differences in carbohydrate hydrolysis strategies. Biotechnol Biofuels. 2016;9:121. https://doi. org/10.1186/s13068-016-0534-X.

20. Shi J, Wang Z, Stiverson JA, Yu Z, Li Y. Reactor performance and microbial community dynamics during solid-state anaerobic digestion of corn stover at mesophilic and thermophilic conditions. Bioresour Technol. 2013;136:574-81. https://doi.org/10.1016/j.biortech.2013.02.073.

21. Gladden JM, Allgaier M, Miller CS, Hazen TC, VanderGheynst JS, Hugenholtz $\mathrm{P}$, et al. Glycoside hydrolase activities of thermophilic bacterial consortia adapted to switchgrass. Appl Environ Microbiol. 2011;77:5804-12. https://doi.org/10.1128/AEM.00032-11.

22. Ilmberger N, Güllert S, Dannenberg J, Rabausch U, Torres J, Wemheuer $B$, et al. A comparative metagenome survey of the fecal microbiota of a breast-and a plant-fed asian elephant reveals an unexpectedly high diversity of glycoside hydrolase family enzymes. PLOS ONE. 2014;9:e106707.

23. Nobu MK, Narihiro T, Rinke C, Kamagata Y, Tringe SG, Woyke T, et al. Microbial dark matter ecogenomics reveals complex synergistic networks in a methanogenic bioreactor. ISME J. 2015;9:1710-22.

24. Vanwonterghem I, Jensen PD, Rabaey K, Tyson GW. Genome-centric resolution of microbial diversity, metabolism and interactions in anaerobic digestion. Environ Microbiol. 2016;18:3144-58.

25. Wilkens C, Busk PK, Pilgaard B, Zhang W, Nielsen KL, Nielsen H, et al. Diversity of microbial carbohydrate-active enzymes in Danish anaerobic digesters fed with wastewater treatment sludge. Biotechnol Biofuels. 2017;10:1-14.

26. Heyer R, Kohrs F, Reichl U, Benndorf D. Metaproteomics of complex microbial communities in biogas plants. Microb Biotechnol. 2015;8:749-63.

27. Artzi L, Bayer EA, Moraïs S. Cellulosomes: bacterial nanomachines for dismantling plant polysaccharides. Nat Rev Microbiol. 2017;15:83-95.

28. Batista-García RA, del Sánchez-Carbente MR, Talia P, Jackson SA, O'Leary ND, Dobson ADW, et al. From lignocellulosic metagenomes to lignocellulolytic genes: trends, challenges and future prospects. Biofuels Bioprod Biorefin. 2016;10:864-82.

29. Terrapon N, Lombard V, Drula E, Coutinho PM, Henrissat B. The CAZy database/the carbohydrate-active enzyme (CAZy) database: principles and usage guidelines. In: Aoki-Kinoshita KF, editor. A practical guide to using glycomics databases. Tokyo: Springer; 2017. p. 117-31.

30. Berlemont R, Martiny AC. Phylogenetic distribution of potential cellulases in bacteria. Appl Environ Microbiol. 2013;79:1545-54.

31. Talamantes D, Biabini N, Dang H, Abdoun K, Berlemont R. Natural diversity of cellulases, xylanases, and chitinases in bacteria. Biotechnol Biofuels. 2016;9:1-11.

32. Weimann A, Trukhina Y, Pope PB, Konietzny SG, McHardy AC. De novo prediction of the genomic components and capabilities for microbial plant biomass degradation from (meta-)genomes. Biotechnol Biofuels. 2013;6:24.

33. Montella S, Ventorino V, Lombard V, Henrissat B, Pepe O, Faraco V. Discovery of genes coding for carbohydrate-active enzyme by metagenomic analysis of lignocellulosic biomasses. Nat Publ Gr. 2017;7:42623.

34. Van Dyk JS, Pletschke BI. A review of lignocellulose bioconversion using enzymatic hydrolysis and synergistic cooperation between enzymesfactors affecting enzymes, conversion and synergy. Biotechnol Adv. 2012;30:1458-80.

35. Yang B, Dai Z, Ding S, Wyman CE. Enzymatic hydrolysis of cellulosic biomass. Biofuels. 2011;2:421-49. 
36. Xu Q, Ding S-Y, Brunecky R, Bomble YJ, Himmel ME, Baker JO. Improving activity of minicellulosomes by integration of intra- and intermolecular synergies. Biotechnol Biofuels. 2013;6:126.

37. Stern J, Moraïs S, Lamed R, Bayer EA. Adaptor scaffoldins: an original strategy for extended designer cellulosomes, inspired from nature. MBio. 2016;7:e00083-16

38. Himmel ME, Xu Q, Luo Y, Ding S-YY, Lamed R, Bayer EA. Microbial enzyme systems for biomass conversion: emerging paradigms. Biofuels. 2010;1:323-41.

39. Koeck DE, Pechtl A, Zverlov W, Schwarz WH. Genomics of cellulolytic bacteria. Curr Opin Biotechnol. 2014;29:171-83.

40. Dam P, Kataeva I, Yang SJ, Zhou F, Yin Y, Chou W, et al. Insights into plant biomass conversion from the genome of the anaerobic thermophilic bacterium Caldicellulosiruptor bescii DSM 6725. Nucleic Acids Res. 2011;39:3240-54.

41. Adams AS, Jordan MS, Adams SM, Suen G, Goodwin LA, Davenport $\mathrm{KW}$, et al. Cellulose-degrading bacteria associated with the invasive woodwasp Sirex noctilio. ISME J. 2011;5:1323-31.

42. Lopez-Mondejar R, Zuhlke D, Vetrovsky T, Becher D, Riedel K, Baldrian P. Decoding the complete arsenal for cellulose and hemicellulose deconstruction in the highly efficient cellulose decomposer Paenibacillus O199. Biotechnol Biofuels. 2016;9:104.

43. Solomon KV, Haitjema CH, Henske JK, Gilmore SP, Borges-Rivera D, Lipzen $A$, et al. Early-branching gut fungi possess a large, comprehensive array of biomass-degrading enzymes. Science. 2016. http://scien ce.sciencemag.org/content/early/2016/02/17/science.aad1431.abstr act.

44. Kolinko S, Wu Y-W, Tachea F, Denzel E, Hiras J, Gabriel R, et al. A bacterial pioneer produces cellulase complexes that persist through community succession. Nat Microbiol. 2017. https://doi.org/10.1038/s4156 4-017-0052-z.

45. Sluiter A, Hames B, Ruiz R, Scarlata C, Sluiter J, Templeton D. Determination of ash in biomass laboratory analytical procedure (LAP) issue date : 7/17/2005 determination of ash in biomass laboratory analytical procedure (LAP). 2008

46. Lovley DR, Greening RC, Ferry JG. Rapidly growing rumen methanogenic organism that synthesizes coenzyme-M and has a high-affinity for formate. Appl Environ Microbiol. 1984;48(1):81-7.

47. Saeman JF, Bubl JL, Harris EE. Quantitative saccharification of wood and cellulose. Ind Eng Chem. 1945;17:35-7.

48. Sluiter A, Hames B, Ruiz R, Scarlata C, Sluiter J, Templeton D, et al. Determination of structural carbohydrates and lignin in biomass. National Renewable Energy Laboratory: Golden; 2008.

49. Baskaran S. Factors for enhanced ethanol production using Clostridium thermosaccharolyticum. Hanover: Dartmouth College; 1996.

50. Steinberg LM, Regan JM. Phylogenetic comparison of the methanogenic communities from an acidic, oligotrophic Fen and an anaerobic digester treating municipal wastewater sludge. Appl Environ Microbiol. 2008;74:6663-71. https://doi.org/10.1128/AEM.00553-08.

51. Lundberg DS, Yourstone S, Mieczkowski P, Jones CD, Dangl JL. Practical innovations for high-throughput amplicon sequencing. Nat Methods. 2013;10:999-1002.

52. Cregger MA, Veach AM, Yang ZK, Crouch MJ, Vilgalys R, Tuskan GA et al. The Populus holobiont: dissecting the effects of plant niches and genotype on the microbiome. Microbiome. 2018;6(1):31.

53. Coman C, Chiriac CM, Robeson MS, Ionescu C, Dragos N, Barbu-Tudoran $\mathrm{L}$, et al. Structure, mineralogy, and microbial diversity of geothermal spring microbialites associated with a deep oil drilling in Romania. Front Microbiol. 2015;6:1-14.

54. Martin M. Cutadapt removes adapter sequences from high-throughput sequencing reads. EMBnet.journal. 2011;17:10. https://doi.org/10.14806 /ej.17.1.200

55. Edgar RC. UPARSE: highly accurate OTU sequences from microbial amplicon reads. Nat Methods. 2013;10:996-8. https://doi.org/10.1038/ nmeth.2604.

56. Caporaso JG, Kuczynski J, Stombaugh J, Bittinger K, Bushman FD, Costello EK, et al. QIIME allows analysis of high-throughput community sequencing data. Nat Methods. 2010;7:335-6.

57. Bokulich NA, Subramanian S, Faith JJ, Gevers D, Gordon Jl, Knight R, et al. Quality-filtering vastly improves diversity estimates from Illumina amplicon sequencing. Nat Methods. 2013;10:57-9.
58. Vázquez-Baeza Y, Pirrung M, Gonzalez A, Knight R. EMPeror: a tool for visualizing high-throughput microbial community data. Gigascience. 2013:2:1-4.

59. Edgar RC. MUSCLE: multiple sequence alignment with high accuracy and high throughput. Nucleic Acids Res. 2004;32:1792-7.

60. Kearse M, Moir R, Wilson A, Stones-Havas S, Cheung M, Sturrock S, et al. Geneious Basic: an integrated and extendable desktop software platform for the organization and analysis of sequence data. Bioinformatics. 2012:28:1647-9.

61. Guindon S, Gascuel O. A simple, fast, and accurate algorithm to estimate large phylogenies by maximum likelihood. Syst Biol. 2003;52:696-704

62. Li D, Liu CM, Luo R, Sadakane K, Lam TW. MEGAHIT: an ultra-fast singlenode solution for large and complex metagenomics assembly via succinct de Bruijn graph. Bioinformatics. 2015;31:1674-6.

63. Pireddu L, Leo S, Zanetti G. Seal: a distributed short read mapping and duplicate removal tool. Bioinformatics. 2011;27:2159-60.

64. Mavromatis K, Ivanova NN, Chen I-MA, Szeto E, Markowitz VM, Kyrpides NC. The DOE-JGI standard operating procedure for the annotations of microbial genomes. Stand Genomic Sci. 2009;1:63-7.

65. Wu Y-W, Simmons BA, Singer SW. MaxBin 2.0: an automated binning algorithm to recover genomes from multiple metagenomic datasets. Bioinformatics. 2016;32:605-7. https://doi.org/10.1093/bioinformatics/ btv638.

66. Kang DD, Froula J, Egan R, Wang Z. MetaBAT, an efficient tool for accurately reconstructing single genomes from complex microbial communities. PeerJ. 2015;3:e1165.

67. Lin H-H, Liao Y-C. Accurate binning of metagenomic contigs via automated clustering sequences using information of genomic signatures and marker genes. Sci Rep. 2016;6:1-8.

68. Parks DH, Imelfort M, Skennerton CT, Hugenholtz P, Tyson GW. CheckM: assessing the quality of microbial genomes recovered from isolates, single cells, and metagenomes. Genome Res. 2015;25:1043-55.

69. Rho M, Tang H, Ye Y. FragGeneScan: predicting genes in short and errorprone reads. Nucleic Acids Res. 2010;38:1-12.

70. Zhao $\mathrm{Y}$, Tang H, Ye Y. RAPSearch2: a fast and memory-efficient protein similarity search tool for next-generation sequencing data. Bioinformatics. 2012;28:125-6.

71. Wu Y-W, Tang Y-H, Tringe SG, Simmons BA, Singer SW. MaxBin: an automated binning method to recover individual genomes from metagenomes using an expectation-maximization algorithm. Microbiome. 2014:2:26.

72. Worm P, Koehorst JJ, Visser M, Sedano-Núñez VT, Schaap PJ, Plugge CM, et al. A genomic view on syntrophic versus non-syntrophic lifestyle in anaerobic fatty acid degrading communities. Biochim Biophys Acta Bioenergy. 2014;1837:2004-16.

73. Caspi R, Billington R, Ferrer L, Foerster H, Fulcher CA, Keseler IM, et al. The MetaCyc database of metabolic pathways and enzymes and the BioCyc collection of pathway/genome databases. Nucleic Acids Res. 2008;36:D623-31.

74. Richter M, Rosselló-Móra R, Oliver Glöckner F, Peplies J. JSpeciesWS: a web server for prokaryotic species circumscription based on pairwise genome comparison. Bioinformatics. 2016:32:929-31.

75. Winkler M-KH, Boets P, Hahne B, Goethals P, Volcke EIP. Effect of the dilution rate on microbial competition: $r$-strategist can win over $\mathrm{k}$-strategist at low substrate concentration. PLoS ONE. 2017;12:e0172785. https:// doi.org/10.1371/journal.pone.0172785.

76. Skennerton CT, Haroon MF, Briegel A, Shi J, Jensen GJ, Tyson GW, et al. Phylogenomic analysis of Candidatus 'Izimaplasma' species: free-living representatives from a Tenericutes clade found in methane seeps. ISME J. 2016;10:2679-92.

77. Izquierdo JA, Pattathil S, Guseva A, Hahn MG, Lynd LR. Comparative analysis of the ability of Clostridium clariflavum strains and Clostridium thermocellum to utilize hemicellulose and unpretreated plant material. Biotechnol Biofuels. 2014;7:136. https://doi.org/10.1186/s1306 8-014-0136-4.

78. Izquierdo JA, Goodwin L, Davenport KW, Teshima H, Bruce D, Detter $C$, et al. Complete genome sequence of Clostridium clariflavum DSM 19732. Stand Genomic Sci. 2012;6:104-15.

79. Shiratori H, Sasaya K, Ohiwa H, Ikeno H, Ayame S, Kataoka N, et al. Clostridium clariflavum sp. nov. and Clostridium caenicola sp. nov., 
moderately thermophilic, cellulose-/cellobiose-digesting bacteria isolated from methanogenic sludge. Int J Syst Evol Microbiol. 2009:59:1764-70

80. Hania WB, Bouanane-Darenfed A, Cayol J-L, Ollivier B, Fardeau M-L. Reclassification of Anaerobaculum mobile, Anaerobaculum thermoterrenum, Anaerobaculum hydrogeniformans as Acetomicrobium mobile comb. nov., Acetomicrobium thermoterrenum comb. nov. and Acetomicrobium hydrogeniformans comb. nov., respectively, and emendation of the genus Acetomicrobium. Int J Syst Evol Microbiol. 2016;66:1506-9. https://doi.org/10.1099/ijsem.0.000910.

81. Ollivier BM, Mah RA, Ferguson TJ, Boone DR, Garcia JL, Robinson R. Emendation of the genus Thermobacteroides: Thermobacteroides proteolyticus sp. nov., a proteolytic acetogen from a methanogenic enrichment. Int J Syst Bacteriol. 1985;35:425-8.

82. Lü F, Bize A, Guillot A, Monnet V, Madigou C, Chapleur O, et al. Metaproteomics of cellulose methanisation under thermophilic conditions reveals a surprisingly high proteolytic activity. ISME J. 2014;8:88-102.

83. Schnürer A, Schink B, Svensson BH. Clostridium ultunense sp. nov., a mesophilic bacterium oxidizing acetate in syntrophic association with a hydrogenotrophic methanogenic bacterium. Int J Syst Evol Microbiol. 1996:46:1145-52.

84. Izquierdo JA, Sizova MV, Lynd LR. Diversity of bacteria and glycosyl hydrolase family 48 genes in cellulolytic consortia enriched from thermophilic biocompost. Appl Environ Microbiol. 2010;76:3545-53.

85. Dassa B, Borovok I, Ruimy-Israeli V, Lamed R, Flint HJ, Duncan SH, et al. Rumen cellulosomics: divergent fiber-degrading strategies revealed by comparative genome-wide analysis of six ruminococcal strains. PLoS ONE. 2014;9:e99221.

86. Krakat N, Westphal A, Schmidt S, Scherer P. Anaerobic digestion of renewable biomass: thermophilic temperature governs methanogen population dynamics. Appl Environ Microbiol. 2010;76:1842-50.

87. Hori T, Sasaki D, Haruta S, Shigematsu T, Ueno Y, Ishii M, et al. Detection of active, potentially acetate-oxidizing syntrophs in an anaerobic digester by flux measurement and formyltetrahydrofolate synthetase (FTHFS) expression profiling. Microbiology. 2011;157:1980-9.

88. Levén L, Eriksson ARB, Schnürer A. Effect of process temperature on bacterial and archaeal communities in two methanogenic bioreactors treating organic household waste. FEMS Microbiol Ecol. 2007:59:68393. https://doi.org/10.1111/j.1574-6941.2006.00263.x.

89. Schmidt A, Müller N, Schink B, Schleheck D. A proteomic view at the biochemistry of syntrophic butyrate oxidation in Syntrophomonas wolfei. PLOS ONE. 2013:8:e56905.

90. Nizami A-S, Korres NE, Murphy JD. Review of the integrated process for the production of grass biomethane. Environ Sci Technol. 2009:43:8496-508. https://doi.org/10.1021/es901533j.

91. Nasir IM, Ghazi TIM, Omar R. Production of biogas from solid organic wastes through anaerobic digestion: a review. Appl Microbiol Biotechnol. 2012;95:321-9.
92. Fan Z, Lynd LR. Conversion of paper sludge to ethanol. I: impact of feeding frequency and mixing energy characterization. Bioprocess Biosyst Eng. 2007;30:27-34.

93. Yilmaz T, Yuceer A, Basibuyuk M. A comparison of the performance of mesophilic and thermophilic anaerobic filters treating papermill wastewater. Bioresour Technol. 2008;99:156-63. https://doi.org/10.1016/J. BIORTECH.2006.11.038.

94. Van Soest PJ. The uniformity and nutritive availability of cellulose. Fed Proc. 1973:32:1804-8.

95. Richard TL. The effect of lignin on biodegradability. Cornell Waste Management Institute. 1996. http://compost.css.cornell.edu/calc/ligni n.html. Accessed 4 Apr 2018.

96. Shao X, Jin M, Guseva A, Liu C, Balan V, Hogsett D, et al. Conversion for Avicel and AFEX pretreated corn stover by Clostridium thermocellum and simultaneous saccharification and fermentation: insights into microbial conversion of pretreated cellulosic biomass. Bioresour Technol. 2011;102:8040-5.

97. Shao X, DiMarco K, Richard TL, Lynd LR. Winter rye as a bioenergy feedstock: impact of crop maturity on composition, biological solubilization and potential revenue. Biotechnol Biofuels. 2015;8:35. https://doi. org/10.1186/s13068-015-0225-z.

98. Maus I, Koeck DE, Cibis KG, Hahnke S, Kim YS, Langer T, et al. Unraveling the microbiome of a thermophilic biogas plant by metagenome and metatranscriptome analysis complemented by characterization of bacterial and archaeal isolates. Biotechnol Biofuels. 2016;9:1-28.

99. Chen CL, Macarie H, Ramirez I, Olmos A, Ong SL, Monroy O, et al. Microbial community structure in a thermophilic anaerobic hybrid reactor degrading terephthalate. Microbiology. 2004;150:3429-40.

100. Hania WB, Godbane R, Postec A, Hamdi M, Ollivier B, Fardeau ML. Defluviitoga tunisiensis gen. nov., sp. nov., a thermophilic bacterium isolated from a mesothermic and anaerobic whey digester. Int I Syst Evol Microbiol. 2012;62:1377-82.

101. Maus I, Cibis KG, Bremges A, Stolze Y, Wibberg D, Tomazetto G, et al. Genomic characterization of Defluviitoga tunisiensis $L 3$, a key hydrolytic bacterium in a thermophilic biogas plant and its abundance as determined by metagenome fragment recruitment. J Biotechnol. 2016;232:50-60.

102. Blumer-Schuette SE, Giannone RJ, Zurawski JV, Ozdemir I, Ma Q, Yin Y, et al. Caldicellulosiruptor core and pangenomes reveal determinants for noncellulosomal thermophilic deconstruction of plant biomass. J Bacteriol. 2012;194:4015-28.

103. Seshadri R, Leahy SC, Attwood GT, Teh KH, Lambie SC, Cookson AL, et al. Cultivation and sequencing of rumen microbiome members from the Hungate1000 Collection. Nat Biotechnol. 2018. https://doi.org/10.1038/ nbt. 4110 .

\footnotetext{
Ready to submit your research? Choose BMC and benefit from:

- fast, convenient online submission

- thorough peer review by experienced researchers in your field

- rapid publication on acceptance

- support for research data, including large and complex data types

- gold Open Access which fosters wider collaboration and increased citations

- maximum visibility for your research: over $100 \mathrm{M}$ website views per year
}

At BMC, research is always in progress.

Learn more biomedcentral.com/submissions 